Document downloaded from:

http://hdl.handle.net/10251/167978

This paper must be cited as:

Garzon-Roca, J.; Sagaseta, J.; Buitrago, M.; Adam, JM. (2021). Dynamic punching assesment of edge columns after sudden corner column removal. ACI Structural Journal. 118(2):299-311. https://doi.org/10.14359/51728195

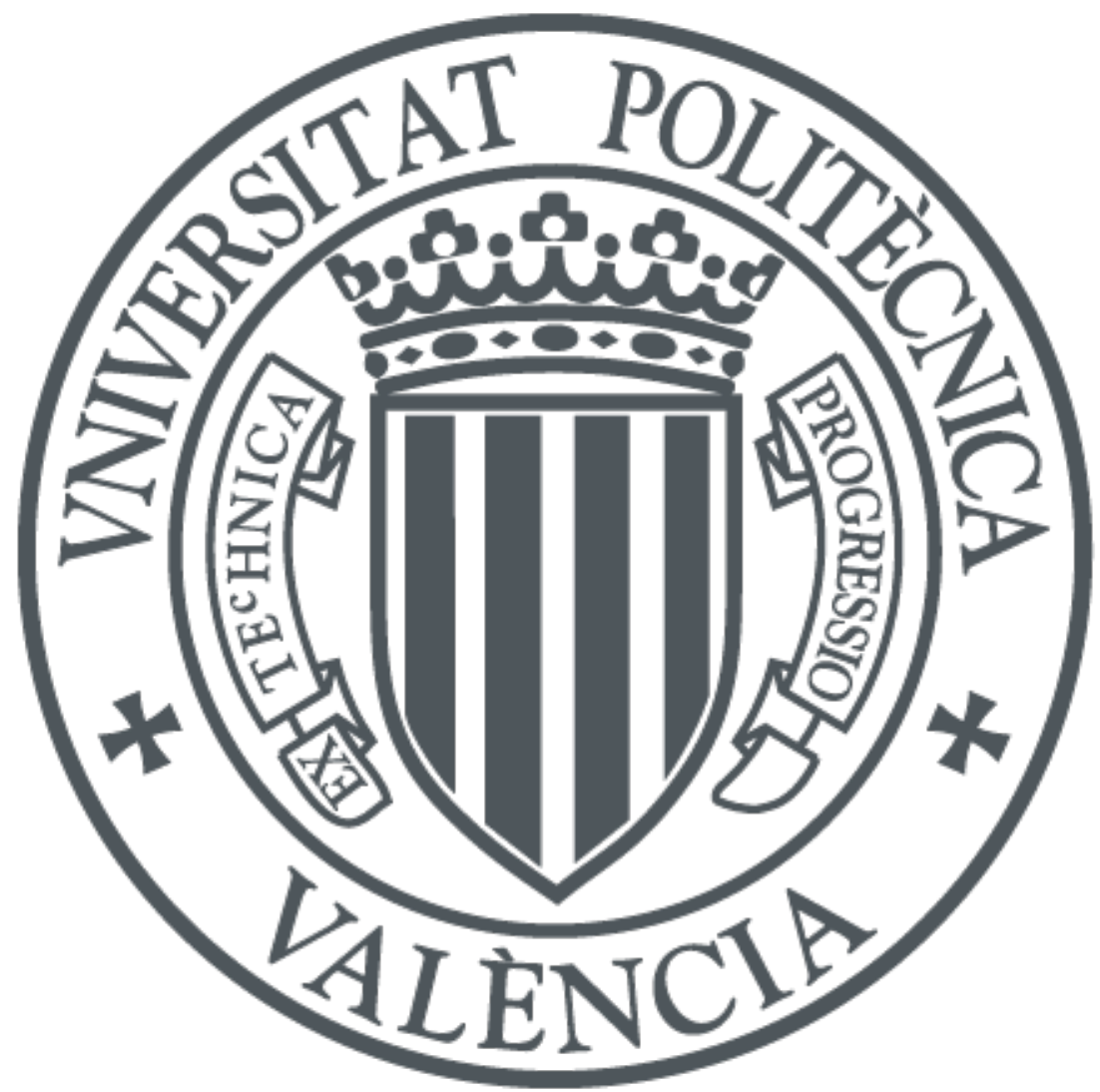

The final publication is available at

https://doi.org/10.14359/51728195

Copyright American Concrete Institute

Additional Information 
Paper accepted for publication (Sept. 2020) in the American Concrete Institute (ACI)

Structural Journal (pending date of publication)

\section{DYNAMIC PUNCHING ASSESMENT OF EDGE COLUMNS AFTER SUDDEN CORNER COLUMN REMOVAL}

by Julio Garzón-Roca ${ }^{1}$, Juan Sagaseta ${ }^{1 *}$, Manuel Buitrago ${ }^{2}$, José M. Adam²

1- University of Surrey, Guildford, United Kingdom

2- Universitat Politècnica de València, Spain

*Corresponding author:

Dr. Juan Sagaseta

University of Surrey

Faculty of Engineering \& Physical Sciences

Guildford, Surrey GU2 7XH UK

Email: j.sagaseta@surrey.ac.uk

\section{Biography:}

Julio Garzón-Roca is a Postdoctoral Researcher at University of Surrey, UK. He received his PhD from Technical University of Valencia (UPV), Spain in 2013. His research interests include experimental and numerical analysis of structural concrete and strengthening of reinforced concrete structures.

Juan Sagaseta is a Senior Lecturer at University of Surrey, UK. He received his $\mathrm{PhD}$ from Imperial College London, UK in 2008. His research interests include shear, punching, strutand-tie modeling, structural concrete under accidental actions and progressive collapse.

Manuel Buitrago is a Postdoctoral Researcher at Universitat Politècnica de València (UPV), Spain. He received his $\mathrm{PhD}$ from UPV in 2018. His research interests include robustness of concrete and steel structures, temporary structures, real-time and structural health monitoring. José M. Adam is a Professor at Universitat Politècnica de València (UPV), Spain. He received his $\mathrm{PhD}$ from UPV in 2008. His research interests include structural assessment, strengtheningretrofitting, structural failures and progressive collapse and robustness. 


\title{
DYNAMIC PUNCHING ASSESMENT OF EDGE COLUMNS AFTER SUDDEN CORNER COLUMN REMOVAL
}

\author{
by Julio Garzón-Roca, Juan Sagaseta, Manuel Buitrago, José M. Adam
}

\begin{abstract}
A dynamic punching shear model is presented for general sudden column removal cases which was validated against data from a purpose-built full-scale two-storey reinforced concrete building subjected to a sudden corner column removal. Such analyses are generally performed in structural robustness or integrity design against progressive collapse and several simplifications are generally adopted to avoid complex dynamic nonlinear analyses. These simplifications are generally on the conservative side and punching can be predicted incorrectly. The test results presented showed that Vierendeel action at small deformations was predominant after column removal. The dynamic amplification of the deformations and shear was significant although punching did not occur as predicted by the model. It was found that in general cases punching around edge columns after sudden corner column removal was not critical using design accidental load combinations, although a dynamic punching check is still needed especially for higher live loads and low flexural and punching reinforcement ratios.
\end{abstract}

Keywords: Dynamic punching shear, structural integrity, progressive collapse, alternative load path, flat slab, column removal.

\section{INTRODUCTION}

Structural robustness or integrity is generally defined as the insensitivity of a structure to local failure. For the case of reinforced concrete flat slab structures, robustness is highly dependent on the structural performance (strength and deformation capacity) of the column-slab connections which is primarily governed by punching shear of the slab around the column. Most codes for building design (e.g. GSA 2013, DoD 2009, EN 1991-1-7-2006) recommend the use of the alternative load path (ALP) method for buildings with medium to high risk of 
progressive collapse. In this approach robustness is demonstrated using the notional sudden column removal method in which perimeter columns, and corner columns in particular (Fig. 1), are commonly selected since they are more vulnerable to accidental actions (e.g. blast, vehicle impact) compared to internal columns. Corner column removal can result in punching of adjacent columns due to the redistribution of loads and inertial effects (dynamic amplification of the shear around the columns).

Experimental research on corner column removal has traditionally focused on framed concrete buildings (e.g. scaled building tests in Xiao et al. 2015; Chen et al. 2015). Tests on flat slabs supported on columns are scarcer and they have mainly been done on sub-assemblies with monotonic (quasi-static) loading (Qian et al. 2013, Lim et al. 2017, Ma et al. 2019) looking at large deflections to activate tensile membrane action (TMA). TMA is often used as a means of last resort against progressive collapse although as shown in Adam et al. (2020), for gravity loads used in ALP design, the deflections obtained after corner column removal can be significantly lower. In such cases where deflections are low, Vierendeel action is predominant in resisting column removal (Fig. 1a) providing an ALP which can be relied on as long as it is demonstrated, through an accurate assessment, that the adjacent column-slab connections have sufficient punching capacity for the dynamic shear demand.

In order to address this question, the analytical dynamic punching assessment model developed in Sagaseta et al. (2017) for sudden internal column removal was extended in this paper for general situations including corner column removal. The work focuses on the response of the adjacent connection until punching. The derivation of the general equations is shown in this paper as well as the validation with test data from a purpose-built full-scale two-storey RC building tested at Universitat Politècnica de Valencia (Adam et al. 2020) to evaluate the dynamic response after sudden corner column removal. The model was further verified using a dynamic non-linear finite element analysis (NLFEA). A parametric study was carried out 
using alternative punching capacity formulae in codes with different flexural and punching shear reinforcement ratios and load combinations to discuss when punching of adjacent columns after column removal is critical in design.

\section{RESEARCH SIGNIFICANCE}

This paper presents a dynamic punching model for general sudden column removal which can be applied to corner column removal. This approach was validated for the first time using a full-scale building test performed by the authors in which Vierendeel action was observed. Sudden corner column removal is commonly adopted in design to prevent progressive collapse, which is challenging due to nonlinear and inertial effects. The problem is generally tackled using either rather simplistic methods (linear static approaches with conservative dynamic increasing factors for the loads) or overly complex methods (advanced dynamic NLFEA). The proposed approach offers a compromise where dynamic amplification factors for punching are obtained analytically using simple but accurate equations.

\section{DYNAMIC PUNCHING ASSESSMENT MODEL FORMULATION}

\section{General overview}

A theoretical analytical model for assessing dynamic punching of adjacent columns due to a sudden internal column removal was developed at University of Surrey (Sagaseta et al. 2017, Nsikak 2018). The model was based on the Critical Shear Crack Theory (CSCT) for punching due to quasi-static loading developed at EPFL by Muttoni and coworkers (Muttoni 2008, Fernández Ruiz and Muttoni 2009, fib 2013) and the Ductility-Centred Robustness Assessment (DCRA) approach developed at Imperial College London by Izzudin and coworkers (Izzudin et al. 2008, Izzudin and Nethercot 2009). The point in common between the CSCT and the DCRA is that both are based on deformations (rather than loads). This compatibility enables the application of energy principles behind dynamic amplification after sudden loads to predict the maximum shear (punching demand) as well as the maximum deflections (i.e. slab rotations 
and hence punching capacity according to the CSCT). Another advantage of using a slab rotation-based approach is that it takes into account the mechanical changes (in span lengths and loading) after the column is removed.

The fundamentals of the dynamic punching assessment model are summarised in Fig. 2 which was initially proposed for internal column removal in Sagaseta et al. (2017). The approach requires three curves: the failure criterion from the CSCT (Muttoni 2008), the shear-rotation relationship for the nonlinear static (flexural) response of the slab near the column given by Model Code 2010 (fib 2013) and the corresponding pseudo-static response after column removal giving the envelope of maximum rotations for different values of shear derived herein using the same principles as in Izzudin and Nethercot (2009). The analytical expressions for these curves are demonstrated and explained in the following three sections.

Overall, the dynamic punching assessment procedure in Fig. 2 is applied in four steps:

(1) Obtain the maximum pseudo-static rotation in the slab $\left(\psi_{p s}\right)$ for the static punching shear demand in the column under study after column removal $\left(V=V_{1}\right)$.

(2) Compute the maximum dynamic punching shear demand $\left(V_{d y n}\right)$ around the column investigated from the nonlinear static shear-rotation response with a rotation $\left(\psi=\psi_{p s}\right)$.

(3) Obtain the dynamic punching shear capacity $V_{R, d y n}$ from the CSCT failure criterion for the same pseudo-static rotation $\left(\psi=\psi_{p s}\right)$.

(4) Compute the demand-capacity ratio $D C R$ defined as ratio $V_{R, d y n} / V_{d y n}$. If $D C R$ is higher than or equal to 1 punching failure is predicted to occur.

The application of the dynamic punching model only requires conducting two static linear finite element analyses (LFEA) of the building: one before column removal (denoted as 0 in parameter subscripts), and one after column removal (denoted as 1 in parameter subscripts). The LFEAs are needed in general cases due to the irregular spans to obtain the shear around the investigated column before $\left(V_{0}\right)$ and after $\left(V_{1}\right)$ column removal as well as moments in the 
column strip and eccentricity factors in the punching formulae (fib 2013). The gravity loads considered in the LFEAs are obtained from codes GSA (2013) or Eurocode (EN 1990-2002) using conventional accidental load combinations as described in later sections.

\section{Nonlinear static shear-rotation response}

Different nonlinear static shear-rotation relationships can be derived from flexural considerations as shown by Muttoni (2008). A pragmatic approach is the parabolic relationship in Model Code 2010 ( $f$ ib 2013) in which the shear and hence the load is proportional to $\psi^{2 / 3}$ where $\psi$ is the slab rotation near the column in the direction from the column of study towards the removed column (i.e. largest rotations). For a Level of Approximation III (LoA III) in Model Code 2010 the shear-rotation before column removal $\left(V \leq V_{0}\right)$ is given by the top expression in Eq. (1):

$\left\{\begin{array}{l}\psi=1.2\left(\frac{r_{s 0}}{d}\right)\left(\frac{f_{y}}{E_{s}}\right)\left(\frac{V}{k_{0} m_{R 0}}\right)^{3 / 2}, \forall V \leq V_{0} \\ \psi=1.2\left(\frac{r_{s 1}}{d}\right)\left(\frac{f_{y}}{E_{S}}\right)\left(\frac{V-\alpha_{s t} V_{0}}{k_{1} m_{R 1}}\right)^{3 / 2}, \forall V \geq V_{0}\end{array}\right.$

where subscripts 0 or 1 (expressed by subscript $i$ onwards) refers to the case considered (before or after column removal respectively); $r_{s i}$ is the distance from the support axis under study to the point of counter-flexure (zero radial bending moment); $d$ is the effective depth of the slab measured to the centroid of the reinforcement layers in tension; $f_{y}$ and $E_{s}$ are the steel yield strength and Young's modulus, respectively; $m_{R i}$ is the average flexural strength per unit width in the column strip and $k_{i}$ is the ratio between the shear and the average moment per unit width $\left(m_{s i}\right)$ at the column strip, i.e. $k_{i}=V_{i} / m_{s i}$ where the moments are taken at the column face and the column strip width $b_{s}$ defined in Model Code 2010 as:

$b_{s}=1.5 \sqrt{r_{s i, x} r_{s i, y}} \leq b_{s r}$ 
where $r_{s i, x}$ and $r_{s i, y}$ are the values of $r_{s i}$ for the two orthogonal directions (Fig. 3) and $b_{s r}$ is a limit in the strip width when the column is near to the slab edge. For a square edge column with one side at the edge of the slab (where $c$ is the column side):

$b_{s r}=0.5\left(b_{s}+c\right)$

Fig. 4 shows the computation of $m_{s i}$ for an edge column in a corner column removal scenario obtained from a LFEA of the building test studied in this paper. The moments include bending and torsional components as normally adopted in design (Wood-Armer moments).

As shown in Fig. 2, at the point of column removal $V=V_{0}$ the curve given by Eq. (1) becomes flatter due the increase of $r_{s i}$ and the reduction of $k_{i}$ (increase of residual spans). The bottom expression in Eq. (1) for $V \geq V_{0}$ follows a similar parabolic relationship using the mechanical parameters resulting from the residual spans after column removal. This curve was derived introducing an offset coefficient $\alpha_{s t}$ which was obtained by imposing that $\psi$ must be the same for a shear $V_{0}$ before and after column removal:

$\alpha_{s t}=1-\left(\frac{r_{s 0}}{r_{s 1}}\right)^{2 / 3} \frac{k_{1} m_{R 1}}{k_{0} m_{R 0}}$

General expression Eq. (4) gives consistent values to those used in Sagaseta et al. (2017) for internal column removal situations with a regular column layout where $r_{s 1} \approx 2 r_{s 0}, k_{0} \approx k_{1}$ and $m_{R 0}=m_{R 1}$, i.e. $\alpha_{s t}=1-0.5^{(2 / 3)}=0.37$.

\section{Pseudo-static response and dynamic load amplification factor}

The maximum slab rotation after a sudden applied load (i.e. maximum dynamic response) is obtained when the kinetic energy of the system is zero and therefore the external work introduced by the gravity loads equals the internal energy absorbed by the system (Izzudin et al. 2009). In a general single degree of freedom system (without damping) where the load applied $P$ is proportional to $u^{a}$, where $u$ is the displacement and $a$ is an exponent coefficient ( $a=1$ for a linear response or $a=2 / 3$ for the parabolic relationship in Model Code 2010), it 
can be demonstrated from energy balance that the dynamic deflection $u_{d y n}$ is the static displacement $u$ times $(1+a)^{1 / a}$. Therefore for a linear response system without damping the dynamic displacement amplification factor is $\lambda_{u}=u_{d y n} / u=2$ as expected whereas for the Model Code 2010 parabolic response $\lambda_{u}=u_{d y n} / u=(5 / 3)^{3 / 2}=2.15$.

The pseudo-static response according to Izzudin et al. 2009 is the applied load versus the maximum displacement obtained from energy balance. The pseudo-static shear-rotation response (Fig. 2) for punching was obtained analytically by multiplying the dynamic deflection amplification factor $\lambda_{u}$ times the increment in rotation in the nonlinear static response Eq. (1) from point $V=V_{0}$ to a general point $V$. The pseudo-static response obtained in this way was:

$\psi_{p s}=1.2\left(\lambda_{u} \frac{r_{s 1}}{d}\right)\left(\frac{f_{y}}{E_{S}}\right)\left[\left(\frac{V-\alpha_{s t} V_{0}}{k_{1} m_{R 1}}\right)^{3 / 2}-\alpha_{p s}\left(\frac{V_{0}}{k_{0} m_{R 0}}\right)^{3 / 2}\right], \forall V \geq V_{0}$

where $\lambda_{u}=2.15$ and coefficient $\alpha_{p s}$ is given by Eq. (6) which was obtained by imposing $\psi_{p s}$ to be the same as the rotation given by Eq. (1) for $V=V_{0}$ :

$\alpha_{p s}=\left(\frac{r_{s 0}}{r_{s 1}}\right)\left(\frac{\lambda_{u}-1}{\lambda_{u}}\right)$

The maximum dynamic rotation of interest is the pseudo-static rotation $\psi_{p s}$ from Eq. (5) with $V=V_{1}$; the corresponding maximum dynamic shear $V_{d y n}$ was estimated from the nonlinear static response Eq. (1) with $\psi=\psi_{p s}$. To simplify the calculations a dynamic load amplification factor $\lambda_{d}$ was defined as the ratio between the dynamic and static shear after column removal which was derived analytically as shown in the Appendix:

$V_{d y n}=\lambda_{d} V_{1}$

$\lambda_{d}=\alpha_{s t} \frac{V_{0}}{V_{1}}+\lambda_{u}^{2 / 3}\left[\left(1-\alpha_{s t} \frac{V_{0}}{V_{1}}\right)^{3 / 2}-\alpha_{d y n}\left(\frac{V_{0}}{V_{1}}\right)^{3 / 2}\right]^{2 / 3}, \forall V_{1} \geq V_{0}$

where coefficient $\alpha_{d y n}$ equals:

$\alpha_{d y n}=\alpha_{p s}\left(\frac{k_{1} m_{R 1}}{k_{0} m_{R 0}}\right)^{3 / 2}=\left(\frac{r_{S 0}}{r_{s 1}}\right)\left(\frac{\lambda_{u}-1}{\lambda_{u}}\right)\left(\frac{k_{1} m_{R 1}}{k_{0} m_{R 0}}\right)^{3 / 2}$ 
The expressions above are applicable to general column removal situations and they are consistent with the expressions in Sagaseta et al. (2017) for internal column removal with a regular column layout where $r_{s 1} \approx 2 r_{s 0}, k_{0} \approx k_{1}$ and $m_{R 0}=m_{R 1}$, i.e. $\alpha_{p s}=\alpha_{d y n} \approx\left(\lambda_{u}-\right.$ 1) $/\left(2 \lambda_{u}\right)=0.26$ using $\lambda_{u}=2.15$.

\section{CSCT failure criterion and dynamic punching shear capacity}

The dynamic punching capacity $V_{R, d y n}$ was obtained from Eq. (10) for a slab rotation $\psi=\psi_{p s}$ from Eq. (5) with $V=V_{1}$. The punching capacity $V_{R}$ in Eq. (10) was calculated according to the CSCT failure criterion (Muttoni 2008, Muttoni and Fernández Ruiz 2009 and Model Code 2010, fib 2013). The main equations are discussed here for completeness:

$V_{R}=V_{R, c}+V_{R, S}$

where $V_{R, c}$ and $V_{R, S}$ are the punching capacity provided by the concrete and the punching reinforcement respectively which are both related to the slab rotation near the column $\psi$. Partial safety factors were not introduced in the resistance as generally adopted in accidental design situations in EN 1991-1-7-2006. The concrete contribution $V_{R, C}$ from Muttoni (2008) is:

$\frac{V_{R, c}}{b_{0} d \sqrt{f_{c}}}=\frac{0.75}{1+15\left(\frac{\psi d}{16+d_{g}}\right)} \quad($ SI units: $\mathrm{N}, \mathrm{mm})$

$\frac{V_{R, c}}{b_{0} d \sqrt{f_{c}}}=\frac{9}{1+15\left(\frac{\psi d}{0.63+d_{g}}\right)} \quad($ US units: $1 \mathrm{~b}$, in $)$

where $f_{c}$ is the concrete compression strength; $d_{g}$ is the maximum aggregate size; $b_{0}$ is the shear-resisting control perimeter defined by:

$b_{0}=k_{e} \min \left(b_{1}, b_{1 r e d}\right)$

where $b_{1}$ is the basic control perimeter at distance $0.5 d$ from the face of the column, limited by the slab edges and drawn to minimize its length (i.e. rounding the corners around the perimeter); $b_{1 \text { red }}$ is the reduced basic control perimeter considering that the length of straight 
segments does not exceed $3 d$; and $k_{e}$ is a eccentricity coefficient that takes into account the concentration of the shear due to moment transfer between the slab and the supported area:

$k_{e}=\frac{1}{1+\frac{e u}{b_{u}}}$

where $e_{u}$ is the total eccentricity of shear with respect to the centroid of the basic control perimeter and $b_{u}$ the diameter of a circle with the same surface as the critical section. For the calculation of $e_{u}$, the critical section may be defined assuming parallel straight lines. A vectoral composition is used when eccentricity in more than one direction exist. Since $k_{e}$ depends on the eccentricity of the support, the value of this parameter (and $b_{0}$ ) changes after column removal; in the punching assessment only $b_{0}$ after column removal was required.

For the punching capacity contribution due to the reinforcement $V_{R, S}$ expressions from Muttoni and Fernández Ruiz (2009) and Model Code 2010 (fib 2013) were adopted:

$V_{R, s}=\sum A_{s w} k_{e} \sigma_{s w} \sin \alpha$

where $\sum A_{s w}$ is the sum of the cross-sectional area of all shear reinforcement intersected by a conical surface with angle $45^{\circ}$ within the zone between $0.35 d$ and $1.0 d$ from the face of the column; $\alpha$ is the angle of the shear reinforcement respect to the horizontal plane and $\sigma_{s w}$ is the stress that is activated in the shear reinforcement:

$\sigma_{s w}=\frac{E_{s} \psi}{6}(\sin \alpha+\cos \alpha)\left(\sin \alpha+\frac{f_{b d}}{f_{y w}} \frac{d}{\phi_{w}}\right) \leq f_{y w}$

where $f_{b d}$ is the bond strength (normally taken as $f_{b d}=3 \mathrm{MPa}[435 \mathrm{psi}]$ ); $\phi_{w}$ is the diameter of the shear reinforcement and $f_{y w}$ is the shear reinforcement yield strength.

\section{COMPARISON WITH EXPERIMENTAL AND NUMERICAL RESULTS}

\section{Validation of punching shear demand against experimental results}

The dynamic punching assessment model was validated using newly available data described in this section corresponding to a purpose-built full-scaled two-storey reinforced concrete building test (Fig. 5a,b) carried out at Universitat Politècnica de València (Adam et al. 2020). 
The test simulated a corner column removal scenario in a building structure consisting of 200 $\mathrm{mm}$ [7.9 in] flat slabs with an effective depth $(d)$ of $158 \mathrm{~mm}$ [6.2 in], supported on nine 300x300 mm [11.8x11.8 in] columns with a regular layout and axis-to-axis spans of $5000 \mathrm{~mm}$ [196.9 in]. Flat beams were placed at the edges (Fig. 5c) to control torsion and deflections. The storey height was $2800 \mathrm{~mm}$ [110.2 in]. The structure was designed according to Eurocodes (EN 1990-2002, EN 1991-1-1-2003, EN 1991-1-7-2006, EN 1992-1-1-2004) for a high occupancy building category and gravity loads only. The average concrete compression strength $\left(f_{c}\right)$ and Young modulus $\left(E_{c}\right)$ at the day of testing were $32 \mathrm{MPa}[4.6 \mathrm{ksi}]$ and $30,150 \mathrm{MPa}[4,373 \mathrm{ksi}]$ respectively. Steel reinforcement yield strength $\left(f_{y}=f_{y w}\right)$ and Young modulus $\left(E_{s}\right)$ were 500 MPa [72.5 ksi] and 200,000 MPa [29,000 ksi] respectively. The flexural reinforcement ratio in punching calculations using the column strip width in Model Code 2010 were $\rho_{0}=1.1 \%$ and $\rho_{1}=1.0 \%$; in this case the column strip width in Eq. (2) varied after column removal due to changes in $r_{s i}$. The punching reinforcement consisted of 10 stirrups per perimeter of $8 \mathrm{~mm}$ [0.31 in] diameter bars (i.e. $\sum A_{s w}=503 \mathrm{~mm}^{2}\left[0.8 \mathrm{in}^{2}\right]$ ) with $100 \mathrm{~mm}$ [3.9 in] radial spacing between perimeters). The corner column removed was a steel girder HE-300B (double T of height and flanges of $300 \mathrm{~mm}$ [11.8 in]) and pinned to the soffit of the first slab (Fig. 5a).

The loads applied in the building were the self-weight and a uniformly distributed load of approximately $5 \mathrm{kN} / \mathrm{m}^{2}\left[0.7 \mathrm{lb} / \mathrm{in}^{2}\right]$ at the corner bay where the column was removed to achieve the most unfavourable situation. The load was introduced with concrete blocks and roughly corresponded to the value specified by GSA (GSA 2013) under accidental situations (1.2DL+0.5LL, where DL is the dead load and LL is the live load). A line load of $0.56 \mathrm{kN} / \mathrm{m}$ simulating a façade was also used in the test although later analyses showed that this had a negligible effect on the results. The column removal was achieved by unlocking a hinge at the middle of the steel column and subsequently destabilizing it with a forklift. Two LVDTs located at $470 \mathrm{~mm}$ [18.5 in] (circa $3 d$ ) from the edge columns (P2 and P6 in Fig. 5) face towards 
the removed corner column (P3; see Fig. 5) were used to measure the vertical slab deflections. The axial loads in the columns were estimated from strains measured in the reinforcement. The shear around the columns was estimated from the column axial force difference above and below the slab, and the slab rotations near the adjacent column $\psi$ were obtained from the vertical displacements measured by the LVDTs. Fig. 6a shows the shear-rotation response for the adjacent column-slab connections obtained experimentally and the predicted response using the proposed model Eqs. (1) and (6). Test measurements were only available after column removal; for comparison, the experimental shear-rotation curve was drawn with the same origin at $V=V_{0}$ as in the predicted nonlinear static response. Two static LFEA models were carried of the entire building using shell elements for the plates and line elements for the columns with the same loading as in the test; from these analyses it was obtained that $V_{0}=95 \mathrm{kN}$ [21.4 kips] and $V_{1}=145 \mathrm{kN}$ [32.6 kips]. Figs. 3 and 4 were also obtained from these analyses; the slenderness slab ratios $r_{s 0} / d$ and $r_{s 1} / d$ were $0.21 L / d$ and $0.35 L / d$, respectively (where $L$ is the axis-to-axis span from the corner column to the edge one), while $k_{0}=3.55$ and $k_{1}=2.63$. The eccentricity coefficient $k_{e}$ estimated from the analyses using Eq. (13) was 0.57 and 0.52 in the model with and without corner column respectively. These values are low compared to the general approximate value of $k_{e}$ for edge columns in Model Code $2010\left(k_{e}=0.7\right)$ due to the relatively large eccentricities in the building investigated (two spans only and eccentric loading) compared to general cases of edge columns with several spans and uniform loading. The comparison between the analytical and the experimental curves in Fig. 6a showed a good correlation. The pseudo-static rotation corresponding to $V_{1}$ gave an accurate prediction of the maximum rotation (dynamic response) in the test and the predicted maximum shear $V_{d y n}=189$ $\mathrm{kN}$ [42.5 kips] was about 5\% higher than test value (178 kN [40.0 kips]). After the column removal the test curve followed the shear-rotation parabola until reaching a maximum shear followed by free vibration oscillations around a constant residual rotation at a shear of around 
$V_{1}$. The dynamic load amplification factor $\lambda_{d}$ obtained from Eq. (8) was 1.31 which was similar to that obtained experimentally (1.24). A further test was carried in the same building using masonry infill walls in the façade at the first floor which resulted in a $20 \%$ increase in $\lambda_{d}$ (Buitrago et al. 2020); this was consistent with the 12\% increase predicted using Eq. (8), keeping $V_{0}$ constant and increasing $V_{1}$ by $60 \%$ as observed in the test.

The dynamic load amplification in the first test by Adam et al. 2020 was further investigated using the readings from the accelerometer placed at the top of the removed column; peak accelerations were similar to gravity, i.e. free fall. An estimation of the inertial forces was carried out after column removal due to the self-weight and live loads using the approximated dynamic approach by Biggs 1964. In this analysis the slab deflections obtained in the LFEA due to gravity loading were converted into inertial forces (with an opposite sign) considering the mass at each slab node and the accelerations measured in the test (based on the measurement at the removed column). An upwards point load was also included representing the reaction of the removed column assuming a linear decay of $0.1 \mathrm{~s}$ (column removal time). The total inertial shear obtained from this analysis at column removal was very close to the maximum punching shear obtained experimentally and the total inertial force reached a value of zero at a similar point as the experimental shear-rotation curve reached the plateau at maximum shear (Fig. 6a). These results confirm some of the assumptions made to estimate the dynamic response as well as the consistency between test measurements.

Fig. $6 \mathrm{~b}$ shows the strain-rates in the test measured locally using Digital Image Correlation (DIC) in the concrete at the top reinforcement at flexural cracks near the edge column on the side of the removed corner column (Fig. 6c). The average strain measurements in the tension chord obtained from DIC were consistent with horizontal LVDTs readings; the ratio between peak (local) and average strains was also consistent with estimations for the observed crack spacings and assuming a typical parabolic distribution of strains between cracks. A peak strain- 
rate of around 0.32/s was obtained after column removal which in concrete structures is normally representative of small dynamic events (e.g. earthquakes or heavy traffic). Micallef et al. (2014) showed that for strain-rates less than 10/s the punching capacity enhancement is negligible and therefore this effect can be ignored (otherwise factor 0.75 in Eq. (11) may be replaced by 0.8 or 1 for strain-rates of 10/s and 100/s respectively).

In conclusion, the punching assessment of the test carried out in this work confirmed that punching was not critical for the geometry and loads in the test. The demand capacity ratio $D C R$ obtained was 0.56 which is well below 1 ; in the calculations $V_{R, d y n}=338 \mathrm{kN}$ [76 kips] which is greater than $V_{d y n}$. The punching capacity obtained using ACI 318 (ACI 318-19, Kamara et al. 2008) and Eurocode 2 (EN 1992-1-1-2004) formulae (see Appendix) were $V_{R, A C I}$ $=230 \mathrm{kN}$ [51.7 kips] and $V_{R, E C 2}=350 \mathrm{kN}$ [78.7 kips]. Further comparison between the results from different punching capacity formulae is presented in the last section.

\section{Verification with non-linear dynamic FEA models}

The building test was further investigated using a dynamic non-linear FEA model (ABAQUS v.2018). The slabs were modelled using shell layered smeared elements (100 mm size) with perfect bond, an elastic-perfectly plastic behaviour for the reinforcement and using the damage plasticity model for the concrete with null Poisson ratio (ABAQUS 2018, Genikomsou and Polak 2015). Shell elements were used in the model to predict the flexural response of the building after column removal; punching was assessed subsequently using the CSCT with the rotations obtained in the FEA. Columns were modelled as linearly elastic and plate constraints were used at the slab nodes intersecting the columns. A column removal time of 0.1s was adopted; factoring this parameter by $1 / 10$ or 2 showed no influence in the results. The results were highly affected by the tensile strength adopted for the concrete $f_{c t}$, giving the formula by Bresler and Scordelis (1963) $\left(f_{c t}=1.9 \mathrm{MPa}[275 \mathrm{psi}]\right)$ the most reasonable predictions of the slab rotations (Fig. 6a). A linear tension-softening was used for the concrete with a maximum 
strain of 0.0025 at $10 \%$ of the maximum tensile stress. The Eurocode 2 (EN 1992-1-1-2004) concrete compression model was used with $f_{c}$ and $E_{c}$ from tests as given in previous section. The stiff numerical prediction before column removal in Fig. 6a was expected since the parabola in Model Code 2010 does not consider cracking nor tension stiffening and also numerical models have a tendency to be stiffer than reality in this range. Despite this, the numerical predictions after column removal were accurate for the parameters adopted (Fig. 6a); the results were consistent with the analytical approach. However, using a slightly different value of $f_{c t}$ in the model, e.g. from Eurocode $2\left(f_{c t}=2.5 \mathrm{MPa}[362 \mathrm{psi}]\right)$ the maximum rotations were around 30\% lower than those shown in Fig. 6a. Further parametric analyses using this model were shown in Garzón-Roca et al. (2020).

\section{PARAMETRIC ANALYSIS}

A parametric analysis was conducted using the proposed dynamic punching assessment model for the same geometry as in the building test described in previous section but with different flexural and punching reinforcement ratios as well as different accidental load combinations and number of floors. The purpose of this analysis was to explore the influence of different acceptable design alternatives on the $D C R$ for punching at the adjacent column after corner column removal. The following cases were considered:

- Reducing flexural reinforcement $\rho_{i}$ to $0.70 \%$ assuming that flat edge beams had not been provided which is not uncommon in practice. For simplicity, all cases studied in the parametric analysis assumed $\rho_{0}=\rho_{1}$.

- Reducing punching reinforcement $\sum A_{s w}$ to $302 \mathrm{~mm}^{2}$ [0.5 in $\left.{ }^{2}\right]$ (i.e. six 8-mm-diameter stirrups spaced at $100 \mathrm{~mm}$ [11.8 in]) which is the minimum reinforcement required from the design calculations (EN 1992-1-1-2004). In practice, the amount of punching reinforcement built always exceeds the amount required due to nominal bar sizes, spacings and in this case due to the edge beams providing additional shear reinforcement. 
- Reducing the uniformly distributed load on the bay to $4 \mathrm{kN} / \mathrm{m}^{2}\left[0.6 \mathrm{lb} / \mathrm{in}^{2}\right]$ which corresponds to the accidental load combination according to Eurocode (EN 1990-2002, EN 1991-1-7-2006), i.e. DL+0.7LL for a high occupancy building category.

- Increasing the uniformly distributed load on the bay to $7 \mathrm{kN} / \mathrm{m}^{2}\left[1.0 \mathrm{lb} / \mathrm{in}^{2}\right]$ which corresponds to an overload (rare) combination according to the Eurocode (EN 1990-2002), i.e. DL+1.5LL representing an extreme accidental situation (Olmati et al. 2017).

- Increasing the number of floors to 4 and 7 to study the influence of the building slenderness and global eccentricity. The new floors had the same geometry and applied loads as the first floor of the original building with the same column size. Introducing a larger number of floors was not practical unless lateral bracing was introduced. A dynamic NLFEA with 10 floors was carried out confirming that the structure was unstable in that case.

Table 1 summarises the 14 cases studied, using the following reference system: ' $X \rho Y \mathrm{~A}_{\mathrm{sw}} Z$ ', where $X$ indicates the loading combination considered, 'GSA' (1.2DL+0.5LL), 'EC2' (DL+0.7LL) or 'OL' for rare overload (DL+1.5LL); $Y$ is equal to $\rho_{i}$ in $\%$; and $Z$ refers to 'bt' if $\sum A_{s w}$ is the built reinforcement provided $\left(503 \mathrm{~mm}^{2}\left[0.8 \mathrm{in}^{2}\right]\right)$ or ' $\mathrm{rq}$ ' if it corresponds to the minimum required from punching design calculations (EN 1992-1-1-2004) (302 mm² [0.5

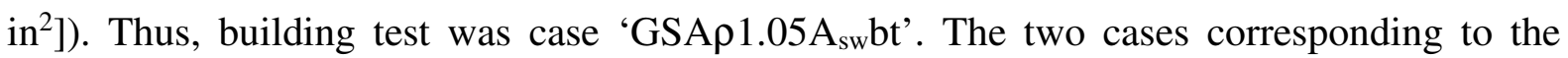
variation in the number of floors were named N4 and N7 for 4 and 7 floors respectively.

\section{Demand-capacity ratio}

As expected, $D C R$ increased in cases with reduced amount of reinforcement $\left(\rho_{i}\right.$ and $\left.A_{s w}\right)$ and higher gravity loads (Table 1). An interesting observation was that the flexural reinforcement ratio $\rho_{i}$ had no influence on the dynamic punching shear demand $V_{d y n}$ as shown in Fig. 7a. A close examination of Eq. (8) for $\lambda_{d}$ showed that $m_{R 1} / m_{R 0} \approx 1$ and $\rho_{i}$ had no influence on other parameters. However, reducing the flexural reinforcement ratio resulted in an increase of the maximum (pseudo-static) rotation (i.e. reduction of the dynamic punching capacity). The 
punching reinforcement ratio had also no influence on the punching demand and a significant influence on the capacity as expected (see Fig. 7a). In the all the cases, the values of $r_{s i}, k_{i}$ and $k_{e}$ from the LFEAs were very similar to the test given in the validation section.

Regarding the effect of increasing number of floors (Fig. 7b), this had a negligible effect on $D C R$ (as well as the rest of parameters in the punching assessment). These results demonstrate that, if lateral stability is controlled by a bracing system, the influence of the slenderness of the structure may be neglected and the LFEAs carried out as part of the assessment could be simplified by modelling only one floor subsystem. It also suggests that carrying out building tests with one or two floors can be representative of taller buildings.

The $D C R$ results in Table 1 suggested that corner column removal is not critical for the edge column design. However, for the case 'GSA $0.70 \mathrm{~A}_{\mathrm{sw}} \mathrm{rq}$ ' similar to the one tested but with the lowest flexural and punching reinforcement ratio allowed in design, $D C R$ was 0.73 which suggest that a punching check was still needed. If $\lambda_{d}$ had be taken as 2 in the calculations (conservative value normally adopted in GSA 2013, DoD 2009) rather than 1.3 estimated analytically (Table 1), DCR would have been similar or larger than 1 in all the cases giving an overly conservative punching assessment. In the most unfavourable case with a rare accidental overload combination, and $\rho_{i}=0.70 \%$, and $A_{s w}=302 \mathrm{~mm}^{2}\left[0.5 \mathrm{in}^{2}\right], D C R$ was 0.92 , which is in the cusp of punching. The accidental overload combination seems very unlikely, however, there are design situations with live loads which can be three times larger than the ones adopted in this work (e.g. floors with areas for storage or industrial facilities, EN 1991-1-1-2003) and therefore a dynamic punching check in such cases is relevant.

\section{Breakdown factors for the demand-capacity ratio}

In order to assess the relative contribution of the mechanical factors behind the increase of DCR after column removal, Eq. (16) was used similarly as in Sagaseta et al. 2017:

$D C R=D C R_{0} \lambda_{d} \Delta_{V} \Delta_{M} \Delta_{S}$ 
where $D C R_{0}$ is the initial demand-capacity ratio or utilization factor $\left(V_{0} / V_{R, 0}\right)$, where $V_{R, 0}$ is the capacity just before column removal (from Eq. (10) with $\psi=\psi_{0}$, where $\psi_{0}$ is the rotation just before column removal from Eq. (1) with $V=V_{0}$, and calculating the shear-resisting control perimeter $b_{0}$ before column removal); $\Delta_{V}$ is the increase ratio of static shear around the column investigated after column removal $\left(\Delta_{V}=V_{1} / V_{0}\right) ; \Delta_{M}$ is the increase ratio of shear demand due to moment transfer increase and $\Delta_{S}$ is the decrease ratio of punching capacity due to the span length increase. The low values of $D C R_{0}$ obtained between 0.2 and 0.3 in all cases reflected that the load combination used in design (1.35DL+1.5LL in EN 1990-2002) was significantly higher than the one used in the column removal case (accidental situation).

The largest contributing factor to the increase in $D C R$ was the increase in dynamic shear demand $\left(\lambda_{d} \Delta_{V}\right)$. The dynamic load amplification factor was $\lambda_{d} \approx 1.3$ in all the cases investigated which was similar to that obtained for interior column removal in previous research (Olmati et al. 2017) and significantly lower than the theoretical $\lambda_{d}=2$ value often adopted in design. The main parameter affecting $\lambda_{d}$ from Eq. (8) was $\Delta_{V}$ as shown in Table 1 which depends mainly on the geometry of the structure and column layout (the same in all the cases investigated) and to less extent it depends on the ratio between the live and dead loads (affecting eccentricities). Factor $\Delta_{V}$ was around 1.5 for the column layout investigated with slightly higher values for cases with higher live loads (higher load imbalance since the live load was applied only in the bay of the removed column). For the corner column removal in this work, the axial load previously carried by the removed column was transmitted to the adjacent edge columns causing a significant unloading in the rear columns which resulted in an additional axial load increment in the column investigated. As pointed out in Adam et al. (2020), the total axial load increment in the adjacent column in the test was of similar value to the load previously carried by the removed corner column. This is different than for interior column removal scenarios where $\Delta_{V}$ is generally obtained assuming that only a fraction of the 
reaction previously carried by the removed column is transmitted to the closest adjacent column. For internal columns, $\Delta_{V}$ is 1.25 for equal spans (loads are redistributed to the four closest columns after column removal) or $\Delta_{V}$ is 1.5 if one span direction is significantly shorter than the other (one-span bending) as demonstrated in Sagaseta et al. (2017).

Moment transfer $\Delta_{M}$ and slenderness $\Delta_{S}$ factors had a lower contribution to $D C R$; depending on the case investigated $\Delta_{M}$ varied from 1.15 to 1.30 and $\Delta_{S}$ varied from 1.00 to 1.20 (Table 1). The values for $\Delta_{M}$ were marginally higher than for internal column removal situations $\Delta_{M} \approx 1.15$ whereas $\Delta_{S}$ was similar (Sagaseta et al. 2017). Higher values of $\Delta_{M}$ and $\Delta_{S}$ corresponded to cases with lower reinforcement ratios and higher loads.

\section{Comparison with other punching capacity formulae}

The $D C R$ was calculated using alternative punching capacity formulae from different codes, ACI 318 (ACI 318-19) and Eurocode 2 (EN 1992-1-1-2004) denoted as $D C R_{A C I}$ and $D C R_{E C 2}$ respectively. The main difference with previous calculations using the CSCT was that the dynamic capacity $V_{R, d y n}$ was replaced by the quasi-static capacity from the load-based formulae in ACI 318 and Eurocode 2. The punching shear demand was calculated as in previous calculations using Eqs. (7) and (8).

The results of $D C R_{E C 2}$ (Table 1) were very similar (within $10 \%$ difference) to those using the CSCT except perhaps for extreme cases with higher loads (overload combination), low flexural reinforcement ratio and high punching reinforcement ratio where $D C R_{E C 2}$ was slightly lower. The lower capacity predicted by the CSCT in such cases was due to the capacity reduction after the increase in slenderness $\left(r_{s i} / d\right)$ which is neglected in Eurocode 2 formulae. These results can vary for different relative column sizes with respect to the slab depth $(c / d)$ as described in Einpaul et al. (2016). It is noteworthy that the slenderness after column removal $\left(r_{s 1} / d\right)$ can be twice the original slenderness; in addition the dynamic amplification of the rotations can also be interpreted as an increased "pseudo-static slenderness" (i.e. term $\lambda_{u} r_{s 1} / d$ in Eq. (5)). The 
maximum pseudo-static slenderness obtained in this work was around 14 which is high compared to punching test data available which normally goes up to slenderness up to 10 (Einpaul et al. 2016); further research is needed for dynamic punching of high slender elements. The results of $D C R_{A C I}$ (Table 1) were more conservative compared to the other approaches; $D C R>1$ in cases with low punching reinforcement ratio and $D C R$ was near 1 in other cases such as the reference test case where punching did not occur. Again, the results can vary for different relative column sizes, e.g. for low reinforcement ratios and medium values of $c / d$, ACI 318 can give higher capacities than both Eurocode 2 and CSCT (Einpaul et al. 2016).

\section{SUMMARY AND CONCLUSIONS}

This paper presents a general dynamic punching model which was used in the analysis of edge columns after the sudden corner column removal in reinforced concrete flat slab buildings. This design scenario is commonly checked in practice as part of the alternative load path approach for demonstrating robustness and susceptibility to progressive collapse of buildings. The proposed model uses the rotation-based CSCT (Muttoni 2008, Fernández Ruiz and Muttoni 2009, fib 2013) for the punching capacity, the nonlinear static shear-rotation response in the Model Code (fib 2013) and the corresponding pseudo-static shear-rotation response from energy balance (Izzudin and Nethercot 2009) which provides the dynamic punching demand. The predictions from the model were compared against experimental results from a purposebuilt full-scale building test carried out by the authors. A parametric study was conducted based on the geometry of the building tested to assess the influence of the main parameters on the $D C R$. From this analytical and experimental work, the following conclusions can be drawn:

(a). In the building test the dynamic amplification of the slab rotations near the column of study after the sudden corner column removal were accurately predicted in the model as well as the maximum punching shear demand. The results were consistent with 
predictions from advanced nonlinear dynamic FEA although, unlike the proposed model, the numerical results were more sensitive to the assumed value of $f_{c t}$.

(b). An advantage of the proposed model is that it only requires to carry out two static LFEAs to estimate the parameters in the analytical expressions to solve the nonlinear dynamic problem. The results obtained using a single floor subsystem model were similar to models with several floors assuming that lateral stability was controlled by suitable bracing. The strain-rate measured in the concrete, controlling the rate at which the critical crack opened, was relatively low (around $0.32 / \mathrm{s}$ ) and therefore the estimated increase in punching capacity due to high-strain rates was negligible.

(c). The dynamic load amplification factor $\lambda_{d}$ obtained analytically was around 1.3 for all the corner column removal cases investigated. The main parameter influencing $\lambda_{d}$ is $\Delta_{V}=V_{1} / V_{0}$ which depends on the geometry and the loading. For the test $\Delta_{V}$ was 1.5 after the transfer of the load previously carried by the corner column to the adjacent edge columns with the additional load transferred from the unloaded rear columns due to the global eccentricity of the loading. The formula for $\lambda_{d}$ provided realistic estimations of the increase in punching shear demand after column removal which is the primary factor affecting $D C R$.

(d). The analysis of different cases using minimum allowable flexural and punching shear reinforcement ratios and extreme accidental load combinations resulted in $D C R$ lower than 1. This suggests that in general design of edge columns adjacent to corner columns, this design scenario is not critical, as observed in the test. However, for higher live loads and lower reinforcement ratios (flexural and punching), DCR can be near 1. In such cases the punching check is clearly justified, especially considering that corner columns are highly vulnerable to accidental actions and in many cases the connection is lightly reinforced (low member forces in persistent design situations). 
(e). The assessment using load-based punching capacity formulae in ACI 318 (ACI 31819) and Eurocode 2 (EN 1992-1-1-2004) showed that the results were rather conservative for the former whereas for the latter the capacity was similar to the CSCT (within 10\%). These results are specific for the cases investigated, i.e. relative column size $c / d=1.9$ and relatively high flexural and punching reinforcement ratios. The CSCT is the only approach that considers the influence of the slenderness on the capacity, which is relevant in column removal scenarios where the pseudo-static slenderness can be around three times the value using the original spans. Future research is needed on punching with higher slenderness and relative column sizes.

(f). This work provided a validation of the dynamic punching shear demand predicted by the model. Further experimental and numerical work is needed to validate further the punching resistance looking at similar sudden column removal tests or numerical simulations where punching failure takes place.

\section{ACKNOWLEDGMENTS}

This work is part of the project funded by the Engineering Physical Science Research Council (EPSRC) of the UK as part of an Impact Acceleration Account (IAA) hold at University of Surrey (EP/K008153/1), and a continuation of two research projects also funded by EPSRC (grant ref: EP/K503939 and EP/K008153/1). The authors would like to acknowledge collaborators at Skidmore, Owings and Merrill (Europe) LLP (Dimitri Jajich and Karl Micallef) and also express their gratitude to the Generalitat Valenciana/Fons Social Europeu [APOSTD/2019/101] for the funding received. The experiment was funded by a 2017 Leonardo Grant for Researchers and Cultural Creators from the BBVA Foundation. 


\section{NOTATION}

$a=$ coefficient of the load-displacement curve in a single degree of freedom system.

$b_{0}=$ shear-resisting control perimeter according to Model Code 2010 (fib 2013).

$b_{1}=$ perimeter of the critical section according to Model Code 2010 (fib 2013).

$b_{1 \text { red }}=$ reduced basic control perimeter according to Model Code 2010 (fib 2013).

$b_{s}=$ strip width

$b_{s r}=$ reduced strip width.

$b_{u}=$ diameter of a circle with the same surface as the critical section defined by $b_{1}$.

$c=$ column side

$d=$ slab effective depth computed from the reinforcement layers centroid in the tension area.

$d_{g}=$ maximum aggregate size

$D C R=$ demand-capacity ratio after column removal following the CSCT criterion.

$D C R_{0}=$ demand-capacity ratio before column removal following the CSCT criterion.

$D C R_{A C I}=$ demand-capacity ratio after column removal following ACI 318 (ACI 318-19).

$D C R_{E C 2}=$ demand-capacity ratio after column removal following Eurocode 2 (EN 1992).

$E_{c}=$ concrete Young modulus

$E_{S}=$ steel Young modulus.

$e_{u}=$ total eccentricity of shear forces with respect to the centroid of the critical section.

$f_{b d}=$ bond strength.

$f_{c}=$ concrete compression strength .

$f_{c t}=$ concrete tension strength .

$f_{y}=$ steel reinforcement yield strength .

$f_{y w}=$ steel punching reinforcement yield strength .

$k_{e}=$ coefficient of eccentricity.

$k_{i}=$ ratio $V_{i} / m_{s i} ; i=0$ and 1 , before and after column removal respectively 
$L=$ axis-to-axis spacing of the columns.

$m_{R i}=$ moment strength per unit width of the column strip before and after column removal.

$m_{s i}=$ average moment per unit width of the column strip before and after column removal.

$m_{x x}=$ flexural moment per unit width along the slab edge.

$m_{x y}=$ torsional moment per unit width of the column strip.

$m_{y y}=$ flexural moment per unit width perpendicular to the slab edge.

$P=$ load applied to a single degree of freedom system.

$r_{s i}=$ distance from the column axis under study to the point of contraflexure in the slab.

$r_{s i, x}=$ value of $r_{s i}$ measured in the parallel direction respect to the edge.

$r_{s i, y}=$ value of $r_{s i}$ measured in the perpendicular direction respect to the edge.

$u=$ deflection of a single degree of freedom system.

$u_{d y n}=$ dynamic deflection of a single degree of freedom system.

$V=$ punching shear demand.

$V_{i}=$ punching shear demand before $(i=0)$ and after column removal $(i=1)$.

$V_{d y n}=$ dynamic punching shear demand in the column under study after column removal.

$V_{R}=$ punching shear capacity.

$V_{R, c}=$ punching shear capacity provided by the concrete.

$V_{R, \text { dyn }}=$ dynamic punching shear capacity according to the CSCT.

$V_{R, S}=$ punching shear capacity provided by the punching reinforcement.

$V_{R, E C 2}=$ punching shear capacity according to Eurocode 2 (EN 1992-1-1-2004).

$V_{R, A C I}=$ punching shear capacity according to ACI 318 (ACI 318-19).

$\alpha=$ angle of the shear reinforcement respect to the horizontal plane.

$\alpha_{d y n}=$ coefficient of the dynamic load amplification factor expression.

$\alpha_{p s}=$ coefficient of the pseudo-static curve expression. 
$\alpha_{s t}=$ coefficient of the load-rotation curve expression.

$\Delta_{M}=$ increase ratio of shear demand due to moment transfer increase.

$\Delta_{S}=$ decrease ratio of punching capacity due to the increase in the span length.

$\Delta_{V}=$ increase ratio of static shear force at the column under study after column removal.

$\lambda_{d}=$ dynamic load amplification factor.

$\lambda_{u}=$ dynamic deflection amplification factor.

$\rho_{i}=$ slab flexural reinforcement ratio; $i=0$ and 1 , before and after column removal respectively

$\sum A_{s w}=$ sum of punching shear reinforcement according to Model Code 2010.

$\sigma_{s w}=$ stress activated in the shear reinforcement.

$\phi_{w}=$ diameter of the shear reinforcement.

$\psi=$ slab rotation

$\psi_{p s}=$ slab rotation obtained by the pseudo-static curve.

\section{REFERENCES}

ABAQUS 2018. Abaqus analysis user's manual. Dassault Systemes Simulia Corp.

ACI Committee 318, "Building Code Requirements for Structural Concrete (ACI 318-19) and Commentary (ACI 318R-19),” American Concrete Institute, Farmington Hills, MI, 2019.

Adam, J.M.; Buitrago, M.; Bertolesi, E.; Sagaseta, J.; and Moragues J.J., "Dynamic performance of a real-scale reinforced concrete building test under a corner-column failure scenario," Eng. Structures, V. 210, 2020, pp. 110414.

Biggs J.M., "Introduction to Structural Dynamics,” McGraw-Hill, New York, 1964.

Bresler, B., and Scordelis, A.C., "Shear strength of Reinforced Concrete Beams," ACI Journal Proceedings, Vol. 60, No. 1, Jan. 1963, pp. 51-74.

Buitrago, M.; Bertolesi, E.; Sagaseta, J.; Calderón, P. A.; and Adam, J. M., "Robustness of RC building structures with infill masonry walls: tests on a purpose-built building." Eng. Structures (under review).

Chen, Q.; Zhao, H.; Zhang, L.; and Wang, T., "Progressive collapse resistance of reinforced concrete frames with specially shaped columns under loss of a corner column," Magazine of Concrete Research, V. 68, No. 9, 2016, pp. 435-449. 
DoD, "Unified Facilities Criteria (UFC): Design of Structures to Resist Progressive Collapse," Department of Defense, Washington D.C., 2009.

Einpaul J.; Bujnak, J. Fernández Ruiz, M.; and Muttoni, A., "Study of the Influence of Column Size and Slab Slenderness on Punching Strength”, ACI Structural Journal, V. 113, No. 1, 2016, pp. 135-145.

EN 1990-2002, "Eurocode 0: Basis of structural design," European Committee for Standardization (CEN), 2002.

EN 1991-1-1-2003, "Eurocode 1: Actions on structures - Part 1-1: Densities, self-weight, imposed loads for buildings," European Committee for Standardization (CEN), 2003.

EN 1991-1-7-2006, "Eurocode 1: Actions on structures - Part 1-7: General actions - Accidental actions," European Committee for Standardization (CEN), 2006.

EN 1992-1-1:2004, "Eurocode 2: Design of Concrete Structures-Part 1: General Rules and Rules for Buildings,” European Committee for Standardization (CEN), 2004.

Fernández Ruiz, M., and Muttoni, A., "Applications of the critical shear crack theory to punching of R/C slabs with transverse reinforcement”, ACI Structural Journal, V. 106, No. 4, 2009, pp. 485-494.

fib, "fib Model code for concrete structures 2010," Fédération Internationale du Béton (fib), Lausanne, Switzerland, 2013.

Garzón-Roca, J.; Sagaseta, J. Buitrago, M.; and Adam, J.M., "Validation of dynamic punching shear assessment after sudden column removal", fib symposium 2020, Concrete Structures for Resilient Society, Shanghai, China, November 2020.

Genikomsou, A.S., and Polak M.A., "Finite element analysis of punching shear of concrete slabs using damaged plasticity model in ABAQUS," Eng. Structures, V. 98, 2015, pp. 38-48. GSA, "Progressive collapse analysis and design guidelines for new federal office buildings and major organization projects," U.S. General Services Administration (GSA), 2013.

Izzudin, B. A., and Nethercot, D., "Design-Oriented Approaches for Progressive Collapse Assessment: Load-Factor vs Ductility-Centred Methods," ASCE Structures Congress, Austin 2009, pp. 800-1791. 
Izzudin, B. A.; Vlassis, A. G.; Elghazouli, A. Y.; and Nethercot, D., "Progressive Collapse of Multi-storey Buildings due to Sudden Column Loss - Part I: Simplified Assessment Framework," Eng. Structures, V. 30, 2008, pp. 1308-1318.

Kamara, M.E.; Novak, L.C.; and Rabbat, B.G., "PCA Notes on ACI 318-08 Building Code Requirements for Structural Concrete," Portland Cement Association, 2008.

Lim, N.S.; Tan, K.H.; and Lee, C.K., "Experimental studies of 3D RC substructures under exterior and corner column removal scenarios," Eng. Structures, V. 150, 2017, pp. 409-427.

Ma, F.; Gilbert, B.P.; Guan, H.; Xue, H.; Lu, X; and Li, Y, "Experimental study on the progressive collapse behaviour of RC flat plate substructures subjected to corner column removal scenarios," Eng. Structures, V. 180, 2019, pp. 7289-741.

Micallef, K.; Sagaseta, J; Fernández Ruiz, M.; and Muttoni, A., “Assessing punching shear failure in reinforced concrete flat slabs subjected to localised impact loading", International Journal of Impact Engineering, V. 71, 2014, pp. 17-33.

Muttoni, A., "Punching Shear Strength of Reinforced Concrete Slabs without Transverse Reinforcement," ACI Structural Journal, V. 105, No. 4, 2008, pp. 440-450.

Nsikak U., "Progressive collapse analysis of reinforced concrete flat slab structures considering post-punching and dynamic response", PhD thesis, Univ. of Surrey, UK, 2018.

Olmati, P.; Sagaseta, J.; Cormie, D.; and Jones, A.E.K., "Simplified reliability analysis of punching in reinforced concrete flat slab buildings under accidental actions," Eng. Structures, V. 130, 2017, pp. 83-98.

Qian, K.; and Li, B., "Experimental study of drop panel effects on response of reinforced concrete flat slabs after loss of corner column”, ACI Structural Journal, V. 110, No. 2, 2013, pp. 319-330.

Sagaseta, J.; Ulaeto, N.; and Russell, J., "Structural robustness of concrete flat slab structures," ACI-fib International Symposium, Punching shear of structural concrete slabs, Philadelphia, PA, 2016, fib Bulletin, V. 81, 2017, pp. 273-298.

Xiao, Y; Kunnath, S; Li, F.W.; Zhao, Y.B.; Lew, H.S.; and Bao, Y., "Collapse test of threestory half scale reinforced concrete frame building," ACI Structural Journal, V. 112, No. 4, 2015, pp. 429-438. 


\section{List of Tables:}

Table 1 - Parametric analysis.

\section{List of Figures:}

Fig. 1 - Corner column removal in concrete flat slab building: (a) notional column removal scenario and Vierendeel action for small deflections (dashed lines); (b) compatibility condition between vertical displacement and slab rotation (cracking shown only near columns).

Fig. 2 - Dynamic punching assessment model.

Fig. 3 - Computation of $r_{s i, x}$ and $r_{s i, y}$ in a corner column removal scenario (LFEA of building test): (a) computation of $r_{s 0, x} ;$ (b) computation of $r_{s 0, y} ;$ (c) computation of $r_{s 1, x} ;(d)$ computation of $r_{s 1, y}$.

Fig. 4 - Computation of $m_{s i}\left(\right.$ LFEA of building test): (a) before column removal $\left(m_{s 0}\right) ;(b)$ after column removal $\left(m_{s 1}\right)$. Note: $c$ is the column size; $b_{s}$ is given by $E q .(2)$ and $b_{s r}$ is given by Eq. (3).

Fig. 5 - Full-scaled two-story RC building tested by Adam et al. (2020); (a) General view; (b) Geometry; (c) Top flexural reinforcement around corner and edge columns (concrete cover 30 mm [1.2 in]); (d) Punching reinforcement around edge columns. Note: dimensions in mm [1 $m m=0.04 \mathrm{in}] ;$ sketches not to scale.

Fig. 6 - Experimental results from full-scale building test: (a) comparison with predicted response from proposed punching assessment; (b) strain-rate of concrete at flexural cracks close to adjacent edge column on the side next to removed corner column measured by DIC; (c) location of the joint measured by DIC with flexural cracks at points 3 and 4 (note: DIC frequency rate $200 \mathrm{~Hz}$; column studied corresponded to P6 according to Adam et al. 2020).

Fig. 7 - Parametric analysis: (a) Influence of flexural and punching reinforcement for the EC2 load combination, CSCT failure criterion corresponds to scenario after column removal (the punching capacity according to ACI (ACI 318-19) were $235 \mathrm{kN}$ [53 kips] for $A_{\text {sw }}$ bt and $170 \mathrm{kN}$ 
[38 kips] for $A_{s w}$ rq; the punching capacity according to Eurocode 2 (EN 1992-1-1-2004) were $355 \mathrm{kN}$ [80 kips] for $\rho=1.05 \%$ and $A_{s w} b t, 270 \mathrm{kN}[61 \mathrm{kips}]$ for $\rho=0.70 \%$ and $A_{s w} b t, 340 \mathrm{kN}$ [76 kips] for $\rho=1.05 \%$ and $A_{s w} r q$, and $250 \mathrm{kN}$ [56 kips] for $\rho=0.70 \%$ and $\left.A_{s w} r q\right) ;(b)$ Influence of number of floors using the GSA load combination (CSCT failure criterion for 2, 4 and 7 floors differs less than 1\% so only the curve for 2 floors after column removal is depicted). 


\section{APPENDIX}

\section{Definition of the dynamic load amplification factor and parameter $\alpha_{d y n}$}

The dynamic load amplification factor $\lambda_{d}$ is the value to which the static punching shear at the column under study $V_{1}$ (after column removal) must be multiplied to obtain the equivalent dynamic punching shear $V_{d y n}$. Graphically, $V_{d y n}$ is obtained by intersecting $V_{1}$ with the pseudo-static curve and then reading the corresponding value of punching shear in the loadrotation curve keeping the slab rotation constant.

According to this, since the slab rotation is constant, for a shear $V=V_{d y n}=\lambda_{d} V_{1}>V_{0}$ value of $\psi$ given by Eq. (1) and $\psi_{p s}$ given by Eq. (5) must be the same. Hence, one can write:

$$
1.2\left(\frac{r_{S 1}}{d}\right)\left(\frac{f_{y}}{E_{S}}\right)\left(\frac{\lambda_{d} V_{1}-\alpha_{S t} V_{0}}{k_{1} m_{R 1}}\right)^{3 / 2}=1.2\left(\lambda_{u} \frac{r_{s 1}}{d}\right)\left(\frac{f_{y}}{E_{S}}\right)\left[\left(\frac{\lambda_{d} V_{1}-\alpha_{S t} V_{0}}{k_{1} m_{R 1}}\right)^{3 / 2}-\alpha_{p s}\left(\frac{V_{0}}{k_{0} m_{R 0}}\right)^{3 / 2}\right]
$$

Doing some mathematical arrangements, Eq. (A1) may be transformed into:

$\lambda_{d}=\alpha_{s t} \frac{V_{0}}{V}+\left[\lambda_{u}\left(1-\alpha_{s t} \frac{V_{0}}{V}\right)^{3 / 2}-\lambda_{u} \alpha_{p s}\left(\frac{k_{1} m_{R 1}}{k_{0} m_{R 0}}\right)^{3 / 2}\left(\frac{V_{0}}{V}\right)^{3 / 2}\right]^{2 / 3}$

where one can group in a coefficient $\alpha_{d y n}$ the term:

$\alpha_{d y n}=\alpha_{p s}\left(\frac{k_{1} m_{R 1}}{k_{0} m_{R 0}}\right)^{3 / 2}=\left(\frac{r_{s, 0}}{r_{s, 1}}\right)\left(\frac{\lambda_{u}-1}{\lambda_{u}}\right)\left(\frac{k_{1} m_{R 1}}{k_{0} m_{R 0}}\right)^{3 / 2}$

Therefore, arriving to:

$\lambda_{d}=\alpha_{s t} \frac{V_{0}}{V_{1}}+\lambda_{u}^{2 / 3}\left[\left(1-\alpha_{s t} \frac{V_{0}}{V_{1}}\right)^{3 / 2}-\alpha_{d y n}\left(\frac{V_{0}}{V_{1}}\right)^{3 / 2}\right]^{2 / 3}, \forall V_{1} \geq V_{0}$

In the case of assessing the effect that a sudden removal of an interior column has on an adjacent interior column, since normally $k_{0} \approx k_{1}$ and $m_{R 0} \approx m_{R 1}$, coefficient $\alpha_{d y n}$ is equal to $\alpha_{p s}$, and approximately 0.53 times the ratio $r_{s 0} / r_{s 1}$ (considering $\lambda_{u}=2.15$ ). 


\section{ACI punching shear capacity}

According to ACI 318 (ACI 318-19), in a two-way slab factored shear stress $v_{u}$ must fulfill:

$v_{u} \leq \phi\left(v_{c}+v_{s}\right)$

where $\phi$ is a strength reduction factor, equal to 0.75 in design but here taken as 1.0 in order to compare with the results given by the CSCT criterion, and $v_{c}$ and $v_{s}$ are the contribution of the concrete and the shear reinforcement, respectively, to the nominal shear strength.

Value of $v_{c}$, taken into account the limitation on this parameter due to having shear reinforcement, is given by Eq. A6 where $f_{c}$ is the concrete compression strength:

$v_{c}=0.17 \sqrt{f_{c}}($ SI units, $\mathrm{MPa})$

$v_{c}=2 \sqrt{f_{c}}$ (US units, psi)

Value of $v_{s}$ is given by:

$v_{s}=\frac{A_{v} f_{y t}}{b_{o} s}$

where $A_{v}$ is the total area of all stirrups legs on a peripheral line geometrically similar to the perimeter of the column section; $f_{y t}$ is the steel yield stress of the stirrups; $s$ is the spacing of the stirrups legs in the direction orthogonal to the column face and $b_{o}$ is the critical perimeter located at $0.5 d$ (where $d$ is the effective depth) and defined assuming parallel straight lines to the column shape but considering the existence of edges or corners. Thus, for a square edge column this critical perimeter is set to:

$b_{0}=3 c+2 d$

where $c$ is the column side.

Factored shear stress $v_{u}$ may be written in terms of the maximum load attainable, $V_{R, A C I}$, as:

$v_{u}=V_{R, A C I}\left(\frac{1}{b_{0} d}+\gamma_{v, p e r p} e_{u, p e r p}\left(\frac{J_{c}}{c}\right)_{p e r p}^{-1}+\gamma_{v, p a r} e_{u, p a r}\left(\frac{J_{c}}{c}\right)_{p a r}^{-1}\right)$

where $\gamma_{v, j}$ is the portion of the moment transferred by eccentricity of the shear load; $e_{u, j}$ is the eccentricity of the shear load respect to the centroid of the critical section defined by $b_{o}$ and 
$\left(\frac{J_{c}}{c}\right)_{j}^{-1}$ is a geometry property of the critical section; subscript $j$ refer to the parallel ('par') or the perpendicular ('perp') direction to the edge. Coefficient $\gamma_{v, j}$ is given as:

$$
\left\{\begin{array}{l}
\gamma_{v, \text { perp }}=1-\frac{1}{1+\frac{2}{3} \sqrt{b_{1} / b_{2}}} \\
\gamma_{v, \text { par }}=1-\frac{1}{1+\frac{2}{3} \sqrt{b_{2} / b_{1}}}
\end{array}\right.
$$

where:

$$
\left\{\begin{array}{l}
b_{1}=c+0.5 d \\
b_{2}=c+d
\end{array}\right.
$$

Term $\left(\frac{J_{c}}{c}\right)_{j}^{-1}$ can be defined as (Kamara et al. 2008):

$$
\left\{\begin{array}{l}
\left(\frac{J_{c}}{c}\right)_{\text {perp }}=\frac{2 b_{1}^{2} d\left(b_{1}+2 b_{2}\right)+d^{3}\left(2 b_{1}+b_{2}\right)}{6 b_{1}} \\
\left(\frac{J_{c}}{c}\right)_{p a r}=\frac{b_{2} d\left(b_{2}+6 b_{1}\right)+d^{3}}{6}
\end{array}\right.
$$

Values of $e_{u, j}$ are calculated as:

$$
\left\{\begin{array}{l}
e_{u, p e r p}=e_{\text {perp }}-c^{\prime}+\frac{c}{2} \\
e_{u, p a r}=e_{\text {par }}
\end{array}\right.
$$

being $e_{\text {perp }}$ and $e_{\text {par }}$ the eccentricity of the shear respect to the column axis in the perpendicular and parallel direction to the slab edge, respectively (obtained in the LFEA), and $c^{\prime}$ the perpendicular distance from the edge to the centroid of the critical section:

$c^{\prime}=\frac{b_{1}\left(b_{1}+b_{2}\right)}{2 b_{1}+b_{2}}$

Eqs. (A5) and (A9) allow computing the maximum load attainable $V_{R, A C I 318}$. For instance, for the full-scaled two-story RC building tested described in the paper, after column removal: $f_{c}=$ $32 \mathrm{MPa}[4.6 \mathrm{ksi}], A_{v}=503 \mathrm{~mm}^{2}\left[0.8 \mathrm{in}^{2}\right], f_{y t}=500 \mathrm{MPa}[73 \mathrm{ksi}], s=100 \mathrm{~mm}[3.9 \mathrm{in}], d=$ $158 \mathrm{~mm}[6.2 \mathrm{in}], c=300 \mathrm{~mm}[11.8 \mathrm{in}], e_{\text {perp }}=401.7 \mathrm{~mm}[15.8 \mathrm{in}]$ and $e_{\text {par }}=320.8 \mathrm{~mm}[12.6$ in], results $v_{c}=0.96 \mathrm{MPa}[139 \mathrm{psi}], v_{s}=2.07 \mathrm{MPa}[300 \mathrm{psi}], \gamma_{v, p e r p}=0.38, \gamma_{v, p a r}=0.42$ and so $V_{R, A C I 318}=230 \mathrm{kN}$ [51.7 kips]. 


\section{Eurocode 2 punching shear capacity}

According to Eurocode 2 (EN 1992-1-1-2004), in a flat slab with punching shear reinforcement, shear stress $v_{u}$ must fulfill:

$v_{u} \leq 0.75 v_{c}+v_{s}$

where $v_{c}$ and $v_{s}$ are the contribution of the concrete and the shear reinforcement, respectively, to the nominal punching shear capacity (note formulation considers that punching shear reinforcement is needed). Value of $v_{c}$ is given by (SI units):

$v_{c}=C_{R d, c} k\left(100 \rho_{l} f_{c}\right)^{1 / 3}$

where $\rho_{l}$ is the flexural reinforcement ratio calculated as the geometric mean of the flexural reinforcement ratio existing in the two orthogonal directions (i.e. $\rho_{l}=\sqrt{\rho_{x} \rho_{y}} \leq 2 \%$ ), and $C_{R d, c}$ and $k$ are two coefficients with a value:

$C_{R d, c}=\frac{0.18}{\gamma_{c}}$

$k=1+\sqrt{\frac{200}{d}} \leq 2$

being $d$ the effective depth and $\gamma_{c}$ the partial safety factor for the concrete, which is here

taken as 1.0 in order to compare with the results given by the CSCT criterion.

Value of $v_{s}$ is given by:

$v_{s}=1.5 \frac{d}{s} \frac{A_{s w} f_{s w, e f}}{u_{1 *} d} \sin \alpha$

where $A_{s w}$ is the area of one perimeter of shear reinforcement around the column; $f_{s w, e f}$ the effective design strength of the punching shear reinforcement; $s$ the radial spacing of perimeters of shear reinforcement; $\alpha$ the angle between the shear reinforcement and the plane of the slab and $u_{1 *}$ the reduced critical perimeter for an edge column, equal to:

$u_{1^{*}}=c+2 \pi d+2 \min (0.5 c, 1.5 d)$

Effective design strength of the punching shear reinforcement, $f_{s w, e f}$, is defined as (in MPa): 
$f_{s w, e f}=250+0.25 d \leq f_{y}$

where $f_{y}$ is the steel yield stress of the stirrups.

Shear stress $v_{u}$ may be written in terms of the maximum load attainable, $V_{R, E C 2}$, as:

$v_{u}=\beta \frac{V_{R, E C 2}}{u_{1} * d}$

where $\beta$ is a coefficient which takes into account the eccentricity of the load and which is calculated as (considering a square column):

$\beta=\frac{u_{1}}{u_{1^{*}}}+0.45 \frac{u_{1}}{W_{1}} e_{\text {par }}$

where $u_{1}$ is the critical perimeter located at $2 d$ and constructed to minimize its length; $e_{\text {par }}$ is the eccentricity of the load respect to the column axis in the parallel direction to the slab edge (obtained by a LFEA) and $W_{1}$ a geometrical property defined for an edge column as:

$W_{1}=\frac{c^{2}}{4}+c^{2}+4 c d+8 d^{2}+\pi d c$

Eqs. (A15) and (A22) allow computing the maximum load attainable $V_{R, E C 2}$. For instance, for the full-scaled two-story RC building experimentally tested described in the paper: $\rho_{l}=1.05 \%$, $f_{c}=32 \mathrm{MPa}[4.6 \mathrm{ksi}], A_{s w}=503 \mathrm{~mm}^{2}\left[0.8 \mathrm{in}^{2}\right], f_{y}=500 \mathrm{MPa}[73 \mathrm{ksi}], s=100 \mathrm{~mm}[3.9 \mathrm{in}]$, $d=158 \mathrm{~mm}[6.2 \mathrm{in}], c=300 \mathrm{~mm}[11.8 \mathrm{in}]$ and $e_{\text {par }}=320.8 \mathrm{~mm}$ [12.6 in], results $v_{c}=1.16$ $\mathrm{MPa}$ [168 psi], $v_{S}=1.37 \mathrm{MPa}[167 \mathrm{psi}], \beta=1.61$ and so $V_{R, E C 2}=350 \mathrm{kN}$ [78.7 kips]. 
Table 1 - Parametric analysis

\begin{tabular}{|c|c|c|c|c|c|c|c|}
\hline Case & $D C R$ & $D C R_{A C I}$ & $D C R_{E C 2}$ & $\lambda_{d}$ & $\Delta_{V}$ & $\Delta_{M}$ & $\Delta_{S}$ \\
\hline GSAp1.05 $\mathrm{A}_{\mathrm{sw}} \mathrm{bt}$ & 0.56 & 0.82 & 0.54 & 1.31 & 1.53 & 1.19 & 1.02 \\
\hline GSA $0.70 \mathrm{~A}_{\mathrm{sw}} \mathrm{bt}$ & 0.61 & 0.82 & 0.57 & 1.31 & 1.53 & 1.19 & 1.06 \\
\hline GSA $1.05 \mathrm{~A}_{\mathrm{sw}} \mathrm{rq}$ & 0.64 & 1.13 & 0.72 & 1.31 & 1.53 & 1.25 & 1.07 \\
\hline GSA $0.70 \mathrm{~A}_{\mathrm{sw}} \mathrm{rq}$ & 0.73 & 1.13 & 0.76 & 1.31 & 1.53 & 1.30 & 1.12 \\
\hline $\mathrm{EC} 2 \rho 1.05 \mathrm{~A}_{\mathrm{sw}} \mathrm{bt}$ & 0.50 & 0.73 & 0.48 & 1.30 & 1.51 & 1.18 & 1.03 \\
\hline $\mathrm{EC} 2 \rho 0.70 \mathrm{~A}_{\mathrm{sw}} \mathrm{bt}$ & 0.51 & 0.73 & 0.51 & 1.30 & 1.51 & 1.20 & 1.00 \\
\hline $\mathrm{EC} 2 \rho 1.05 \mathrm{~A}_{\mathrm{sw}} \mathrm{rq}$ & 0.55 & 1.01 & 0.64 & 1.30 & 1.51 & 1.23 & 1.07 \\
\hline $\mathrm{EC} 2 \rho 0.70 \mathrm{~A}_{\mathrm{sw}} \mathrm{rq}$ & 0.60 & 1.01 & 0.68 & 1.30 & 1.51 & 1.29 & 1.07 \\
\hline OLp1.05 $\mathrm{A}_{\mathrm{sw}} \mathrm{bt}$ & 0.64 & 0.95 & 0.62 & 1.32 & 1.55 & 1.19 & 1.00 \\
\hline OLp0.70A $\mathrm{A}_{\mathrm{sw}} \mathrm{bt}$ & 0.75 & 0.95 & 0.65 & 1.32 & 1.55 & 1.15 & 1.16 \\
\hline OLp1.05 $\mathrm{A}_{\mathrm{sw}} \mathrm{rq}$ & 0.75 & 1.31 & 0.82 & 1.32 & 1.55 & 1.27 & 1.07 \\
\hline OL $\rho 0.70 \mathrm{~A}_{\mathrm{sw}} \mathrm{rq}$ & 0.92 & 1.31 & 0.88 & 1.32 & 1.55 & 1.29 & 1.20 \\
\hline $\mathrm{N} 4$ & 0.56 & 0.83 & 0.54 & 1.31 & 1.54 & 1.20 & 1.01 \\
\hline $\mathrm{N} 7$ & 0.60 & 0.85 & 0.57 & 1.33 & 1.61 & 1.20 & 1.02 \\
\hline
\end{tabular}

Note: 'GSAp1.05Aswbt' corresponds to the building test. 

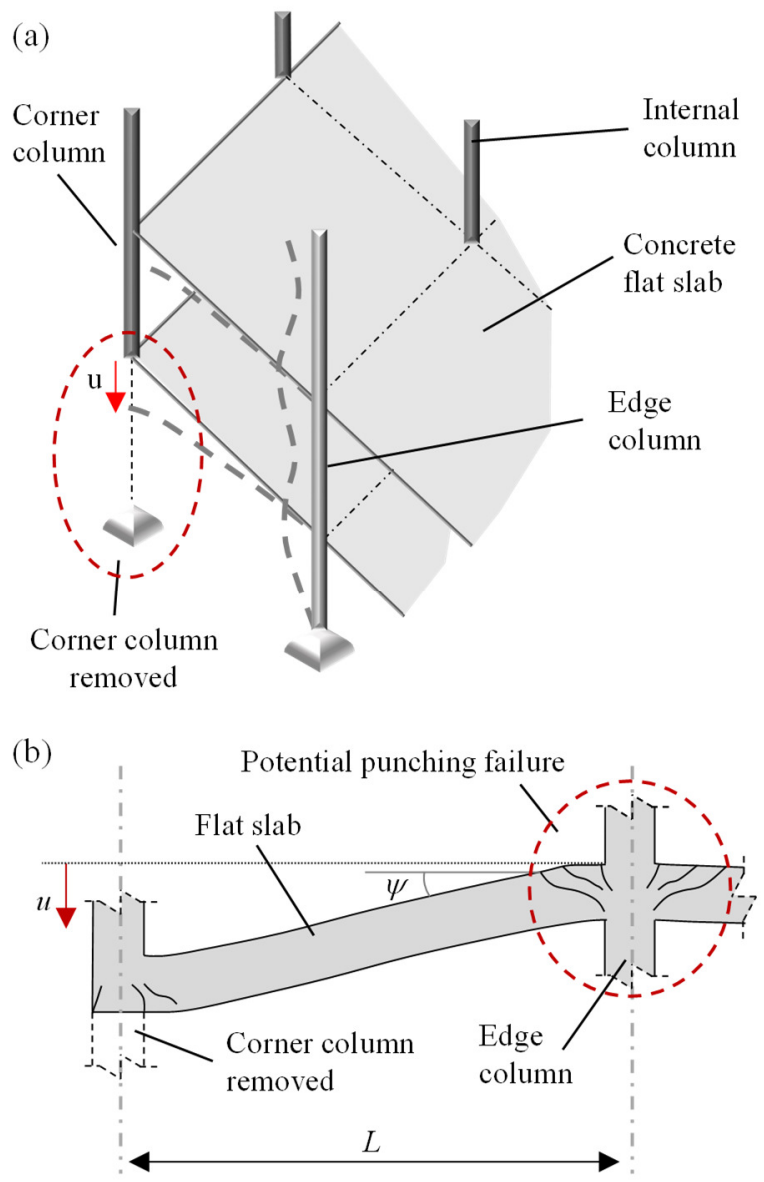

Fig. 1 - Corner column removal in concrete flat slab building: (a) notional column removal scenario and Vierendeel action for small deflections (dashed lines); (b) compatibility condition between vertical displacement and slab rotation (cracking shown only near columns). 


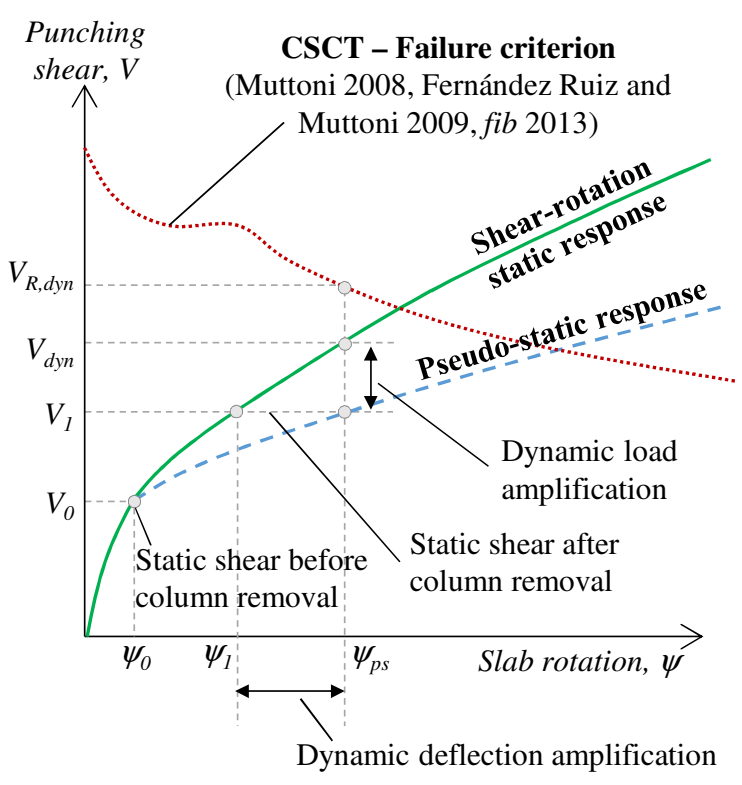

Fig. 2 - Dynamic punching assessment model. 
(a)

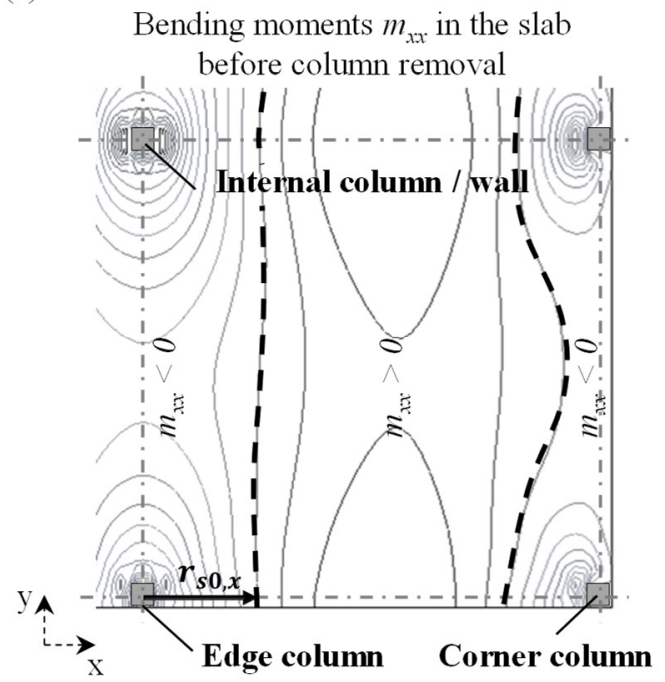

(c)

Bending moments $m_{x x}$ in the slab

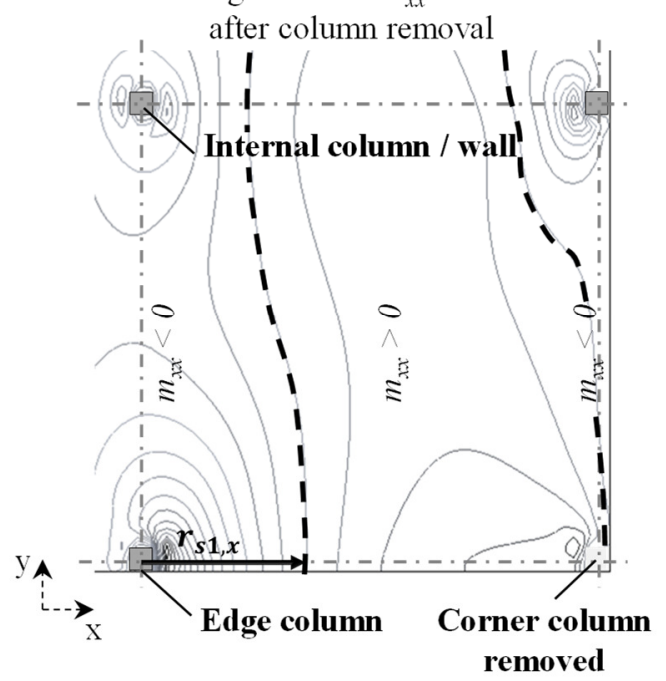

(b)

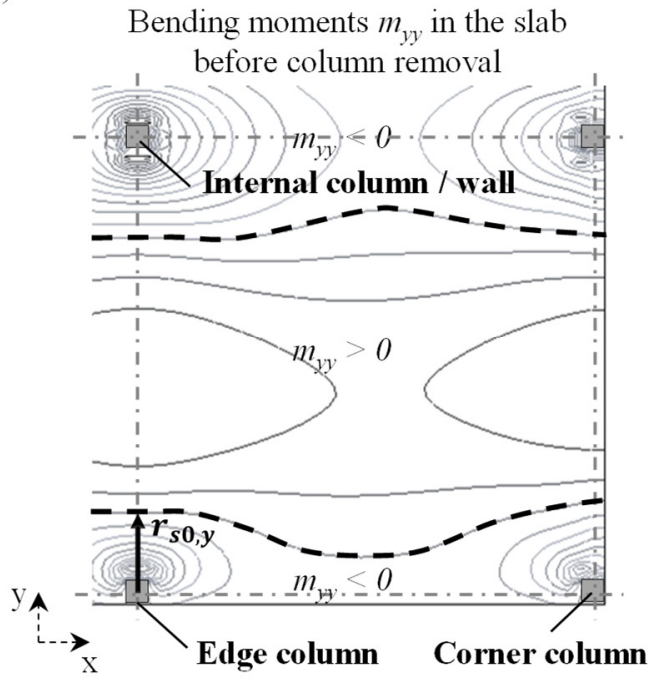

(d)

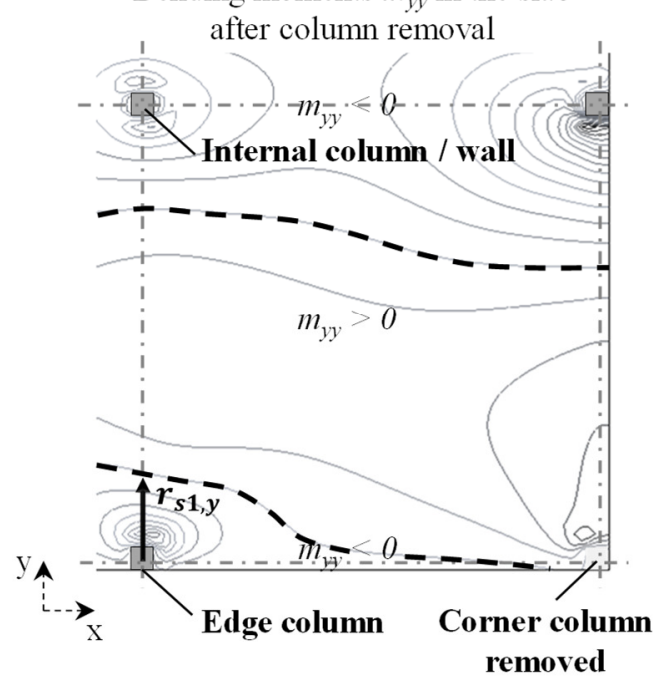

Fig. 3 - Computation of $r_{s i, x}$ and $r_{s i, y}$ in a corner column removal scenario (LFEA of building test): (a) computation of $r_{s 0, x}$; (b) computation of $r_{s 0, y}$; (c) computation of $r_{s 1, x} ;$ (d) computation of $r_{s 1, y}$. 

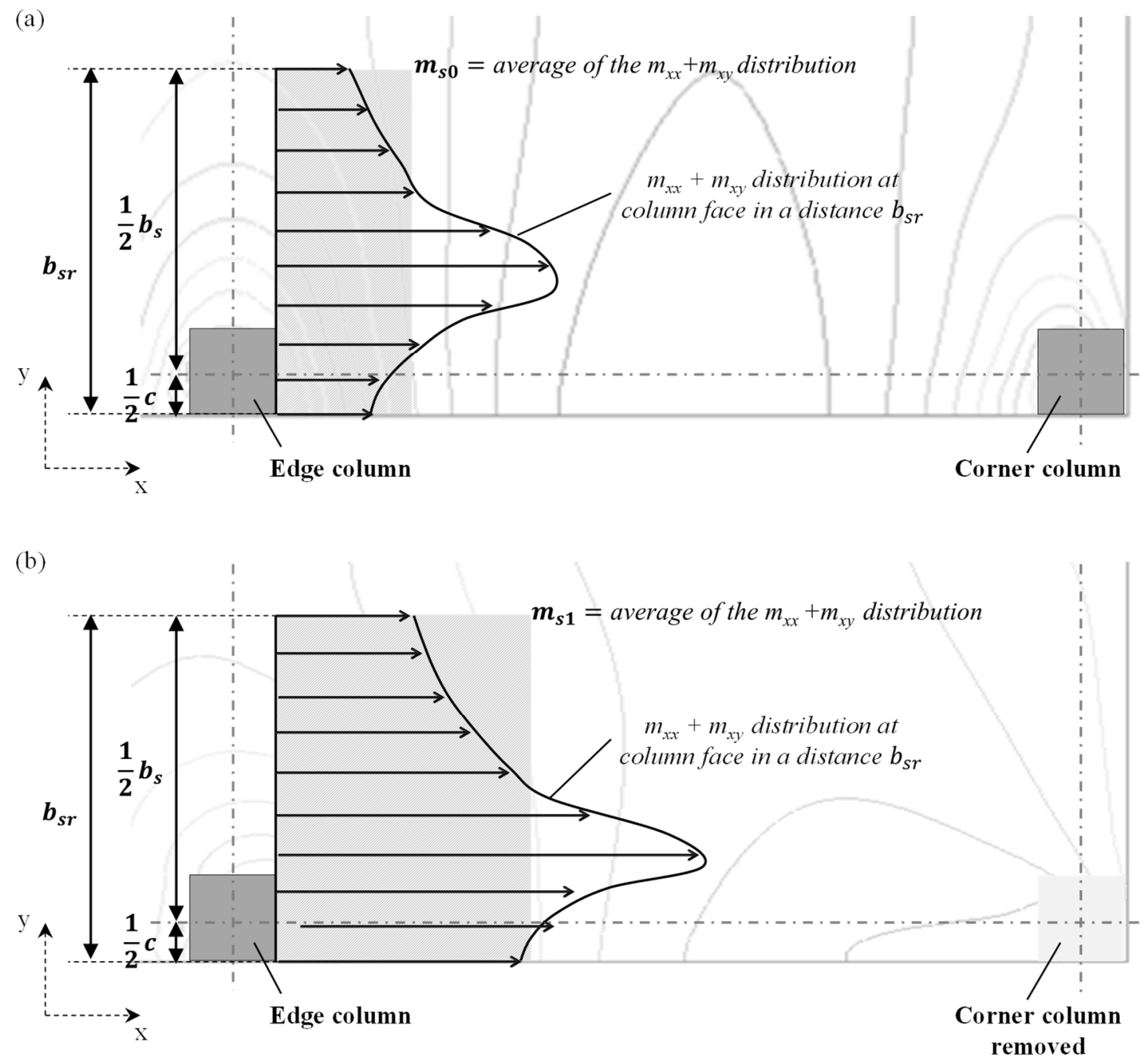

Fig. 4 - Computation of $m_{s i}$ (LFEA of building test): (a) before column removal $\left(m_{s 0}\right)$; (b) after column removal $\left(m_{s 1}\right)$. Note: $c$ is the column size; $b_{s}$ is given by Eq. (2) and $b_{s r}$ is given by Eq. (3). 
(a)

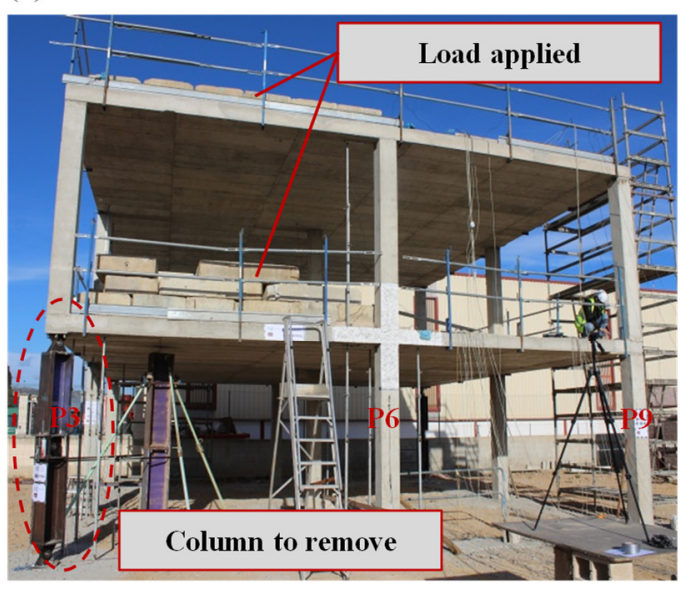

(c)
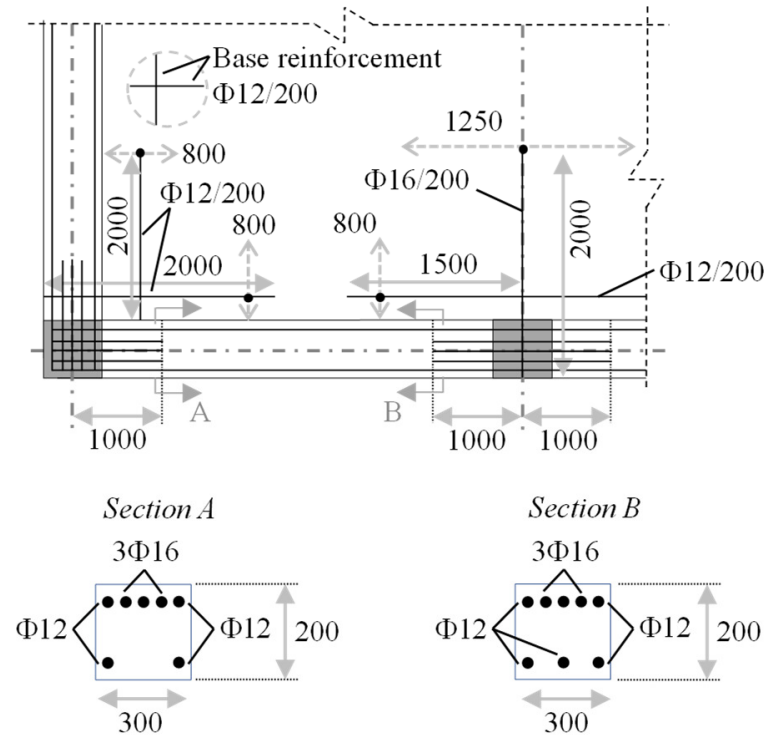

(b)

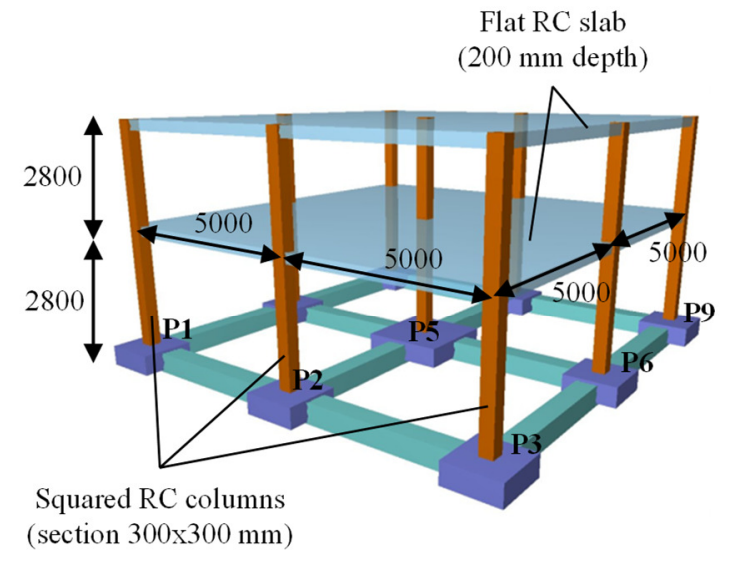

(d)

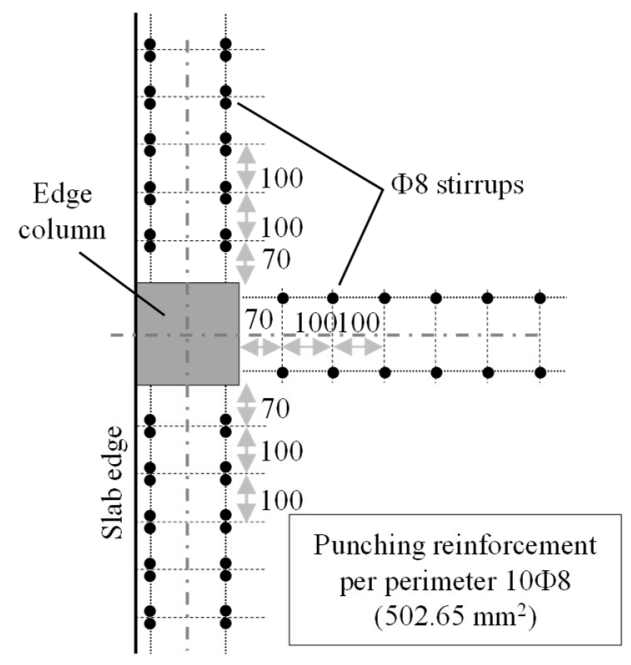

Fig. 5 - Purpose-built full-scaled two-story RC building tested by Adam et al. (2020); (a) General view; (b) Geometry; (c) Top flexural reinforcement around corner and edge columns (concrete cover $30 \mathrm{~mm}$ [1.2 in]); (d) Punching reinforcement around edge columns. Note: dimensions in $\mathrm{mm}$ [1 $\mathrm{mm}=0.04 \mathrm{in}]$; sketches not to scale. 
(a)

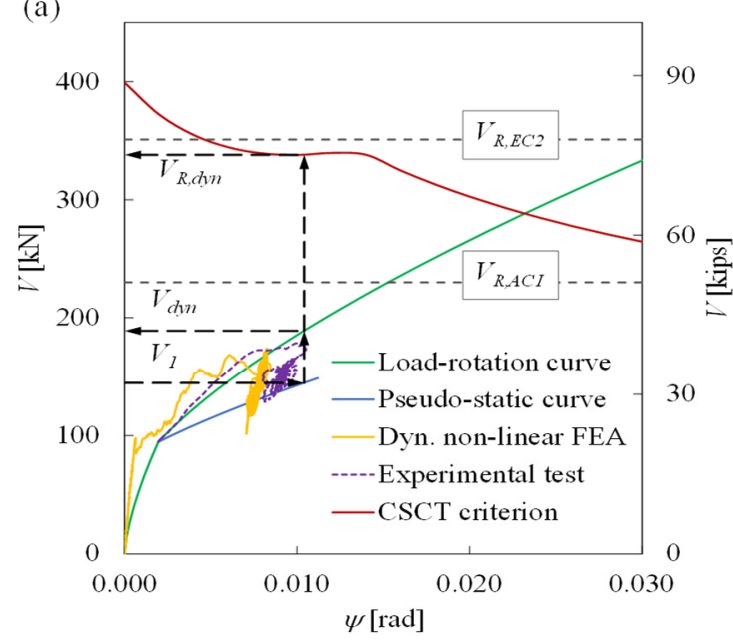

(b)

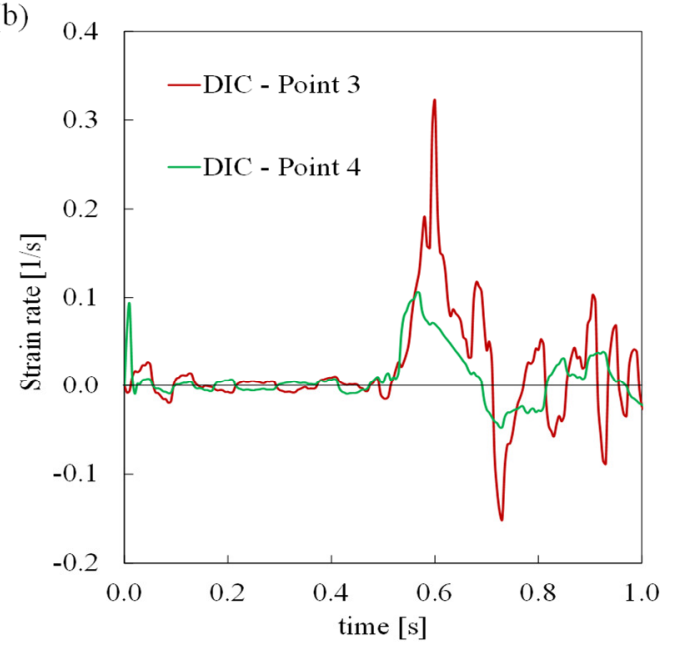

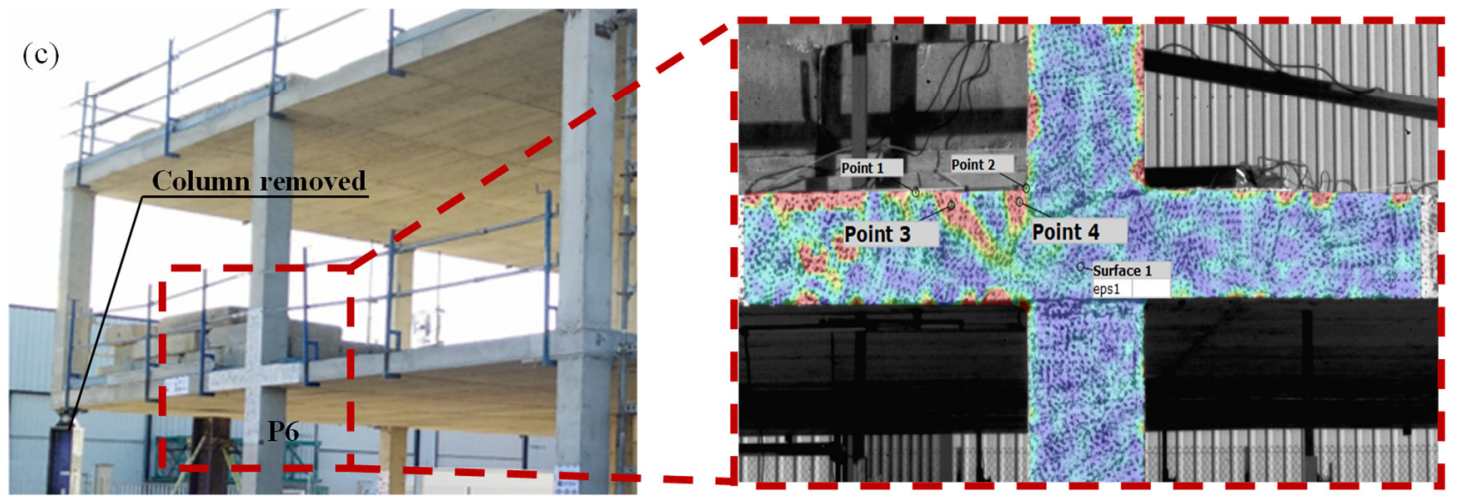

Fig. 6 - Experimental results from full-scale building test: (a) comparison with predicted response from proposed punching assessment; (b) strain-rate of concrete at flexural cracks close to adjacent edge column on the side next to removed corner column measured by DIC; (c) location of the joint measured by DIC with flexural cracks at points 3 and 4 (note: DIC frequency rate $200 \mathrm{~Hz}$; column studied corresponded to P6 according to Adam et al. 2020). 

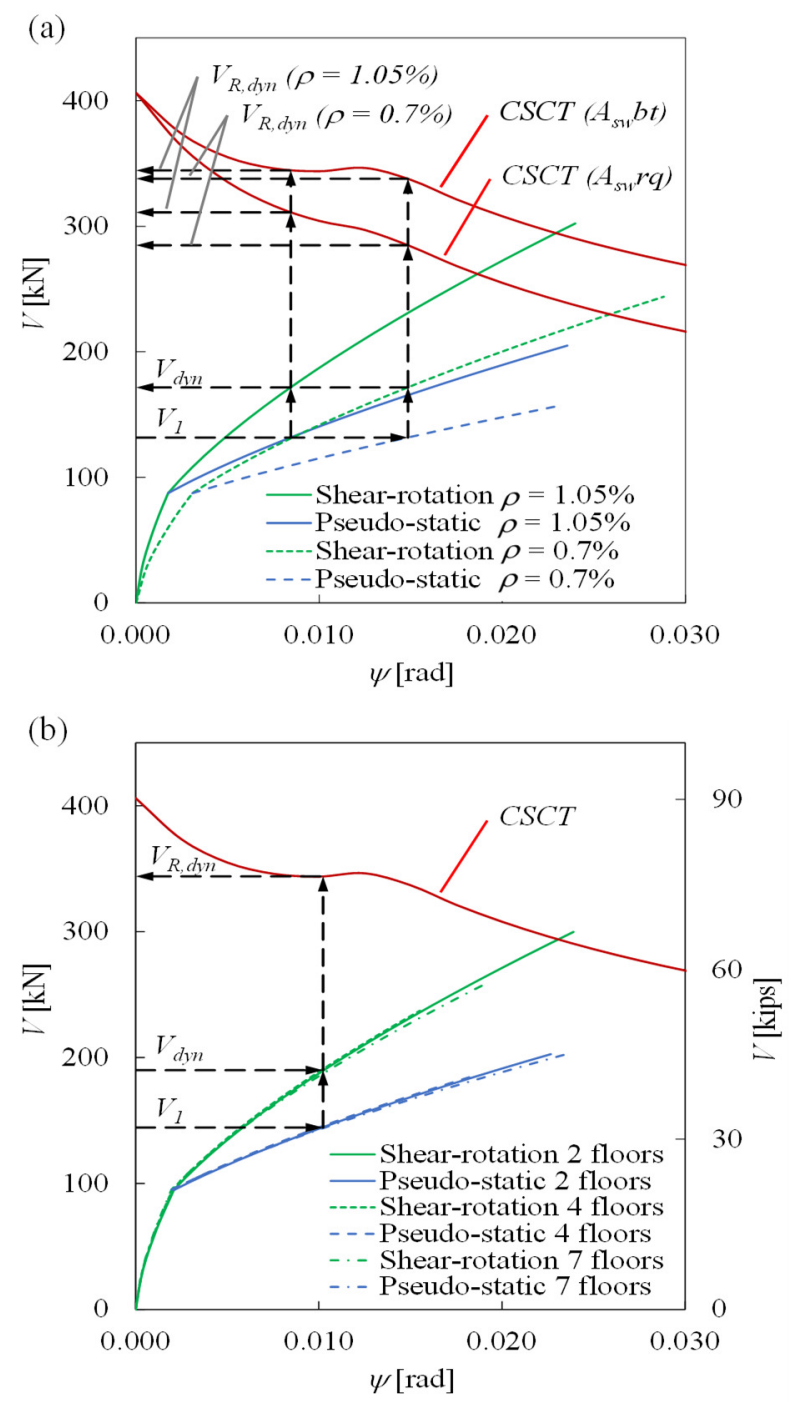

Fig. 7 - Parametric analysis: (a) Influence of flexural and punching reinforcement for the EC2 load combination, CSCT failure criterion corresponds to scenario after column removal (the punching capacity according to ACI (ACI 318-19) were $235 \mathrm{kN}\left[53 \mathrm{kips}\right.$ ] for $\mathrm{A}_{\mathrm{sw}} \mathrm{bt}$ and $170 \mathrm{kN}$ [38 kips] for $A_{\mathrm{sw}} \mathrm{rq}$; the punching capacity according to Eurocode 2 (EN 1992-1-1-2004) were $355 \mathrm{kN}$ [80 kips] for $\rho=1.05 \%$ and $\mathrm{A}_{\mathrm{sw}} \mathrm{bt}, 270 \mathrm{kN}$ [61 kips] for $\rho=0.70$ and $\mathrm{A}_{\mathrm{sw}} \mathrm{bt}, 340 \mathrm{kN}$ [76 kips] for $\rho=1.05 \%$ and $A_{s w}$ rq, and $250 \mathrm{kN}$ [56 kips] for $\rho=0.70 \%$ and $A_{s w} r q$ ); (b) Influence of number of floors using the GSA load combination (CSCT failure criterion for 2, 4 and 7 floors differs less than $1 \%$ so only the curve for 2 floors after column removal is depicted). 